NIST

PUBLICATIONS

\section{FTAM INTEROPERABILITY TESTS}

Carol A. Edgar Coordinator, NIST

U.S. DEPARTMENT OF COMMERCE Natlonal Institute of Standards and Technolosy

Calthersburg, MD 20899
$Q C$

100

.056

\#4435

1990

C. 2
U.S. DEPARTMENT OF COMMERCE Robort A. Mosbachor, seerotary MTIONAL INSTIUTE OF STANAFOS AND TECHNOLOQY

John W. Lyone, Directer 
NATONAL DUSTIUTE OF STANDARDS \&
TECHTOLOGY Research Information Center

Gaithersburr: MD 2089

\section{DATE DUE}

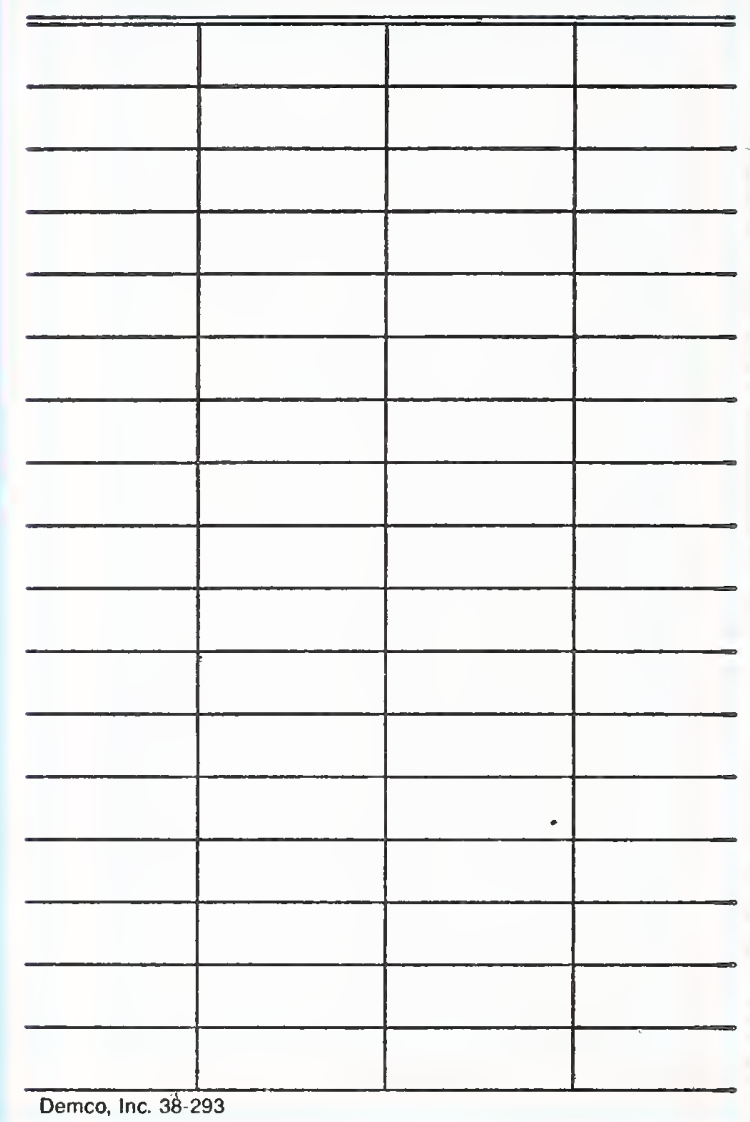




\section{FTAM INTEROPERABILITY TESTS}

\section{Carol A. Edgar Coordinator, NIST}

U.S. DEPARTMENT OF COMMERCE Natlonal Institute of standards and Technology

Galthersburg, MD 20899

August 1990

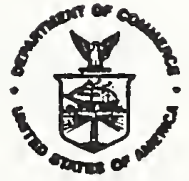

U.S. DEPARTMENT OF COMMERCE Robert A. Mosbachor, Secretary MATIONAL INSTIUUE OF GTANDAROS AND TECMNOLOQY

John W. Lyons, Director 



\section{FTAM Interoperability Tests}

Table of Contents

1. Introduction

2. Overview

2.1 Test Cases

2.2 Test Files

2.3 Connections

2.4 Test Suites

3. FTAM Interoperability Tests 7

3.1 FTAM-1 Test Cases 1

$\begin{array}{lll}3.2 & \text { FTAM-2 Test Cases } & 10\end{array}$

3.3 FTAM-3 Test Cases 14

$\begin{array}{lll}3.4 & \text { NBS-6 Test Cases } & 17\end{array}$

$\begin{array}{ll}3.5 & \text { NBS-7 Test Cases }\end{array}$

3.6 NBS-8 Test Cases 33

3.7 NBS-9 Test Cases 44

3.8 Limited File Management Test Cases $\quad 45$

3.9 Enhanced File Management Test Cases 50

4. Test Files and Their Contents 54

4.1 Files Used By FTAM-1 Test Cases 55

4.2 Files Used By FTAM-2 Test Cases 58

4.3 Files Used By FTAM-3 Test Cases 60

4.4 Files Used By NBS-6 Test Cases 64

4.5 Files Used By NBS-7 Test Cases 67

4.6 Files Used By NBS-8 Test Cases . 72

4.7 Files Used By Limited File Management Test Cases 77

4.8 Files Used By Enhanced File Management Test Cases 80

5. Cross Reference Table $\quad 82$

6. Programs Substantiating The FTAM-1 and FTAM-3 Test Files 86

Appendix A. FTAM Interoperability Requirements for GOSIP 102

Appendix B. Connection Parameters 106 



\section{FTAM Interoperability Tests}

\section{Introduction}

This document contains the File Transfer, Access and Management (FTAM) interoperability test suite that was originally developed by the OSINET Technical Committee. OSINET is a regional network that was established to promote OSI through activities related to interoperation testing. This interoperability test suite has been coordinated internationally through OSINET's participation in OSIone, an association of regional OSI networks.

Special acknowledgement is given to John Dempsey, Unisys Corporation, who acted as the editor of the FTAM Interoperability Test Suite for OSINET.

\section{Overview}

The File Transfer, Access and Management (FTAM) standard enables users to transfer, access and manage large groups of information in a consistent manner within an open environment. This document defines FTAM interoperability tests designed to test the interoperability between FTAM implementations supplied by different vendors. Implementations are assumed to be based on the FTAM International Standard (IS 8571) [1-4].

Interoperability testing tests the ability to perform overall operations between two or more vendor specific implementations. Examples of FTAM operations are send a complete file to a remote system, delete a file from a remote system, and replace a specified data unit in a file on a remote system. The complexity of OSI protocols makes exhaustive testing impractical on both technical and economic grounds. Furthermore, there is no guarantee that a system which has passed a set of interoperability tests will interoperate with other systems or conform to any specification. Rather, passing the tests provides a level of confidence that the system will likely interoperate with other systems and should behave in a consistent manner in representative instances of communication.

The following sections explain the organization of the FTAM interoperability test suite. Developers of OSI profiles (e.g., NIST, TOP) may specify the set of tests that must be successfully completed to meet their requirements. (See Appendix A.) Test participants are free to select additional tests to run from the remaining optional tests. Additional tests may be added in the future to satisfy the requirements of national and international profile developers.

\subsection{Test Cases}

The tests are written from the point of view of the initiator. The FTAM roles that can be tested are: initiator-sender, initiator-receiver, responder-sender, and responder-receiver. 
The FTAM test cases are organized by document types and management attributes. Each test case is defined by:
1. Name
2. Purpose
3. Procedure
4. Pass Condition

The naming convention used to uniquely identify a test name is as follows. The first component identifies the document type or management attribute for which the test case is written. Values for the first component are:

FTAM1 - FTAM-1 Document Type
FTAM2 - FTAM-2 Document Type
FTAM3 - FTAM-3 Document Type
NBS6 - NBS-6 Document Type
NBS7 - NBS-7 Document Type
NBS8 - NBS-8 Document Type
NBS9 - NBS-9 Document Type
LFM
EFM

The second component identifies the action that the test case performs. This component is not used for naming management attribute test cases. Values for the possible actions are:

$\begin{array}{lll}\text { R } & \text { - } & \text { Read } \\ \text { W } & - & \text { Write } \\ \text { RR } & - & \text { Multiple Reads } \\ \text { WW } & - & \text { Multiple Writes } \\ \text { RW } & - & \text { Multiple Reads and Writes }\end{array}$

A read action corresponds to the initiator-receiver/responder-sender role. A write action corresponds to the initiator-sender/responder-receiver role. And, read and write corresponds to the initiator-receiver/responder-sender and initiator-sender/responder-receiver role. The single characters ' $R$ ' and 'W' are used by the transfer and access service class tests. The "RR", "WW", and "RW" are used by the access service class tests.

The last component identifies the test case number. Test case numbers are used to distinguish between those test cases where the name of the first three components are the same. 
Next, the test purpose briefly describes the capability being tested.

The test procedure defines the steps that the initiator needs to carry out to run the test. The procedure is written from the point of view of the initiator. For example, in the test named FTAM1-R-1, the procedure is:

Read the complete file R1R1 and store the received contents into file A1R1.

The actual steps described may not correspond directly to a particular FTAM implementation, and added operations may be needed in order to perform the test.

The pass condition provides the criteria for determining whether or not a test has successfully passed. Continuing our above example, the pass condition for the test case FTAM1-R-1 is:

The initiator verifies that the contents of file A1R1 are identical to the contents defined for file R1R1.

To verify that the contents of two files are the same (in this example, files A1R1 and R1R1), their virtual filestore representations must be compared. The contents of the virtual filestore representations of the two files should be identical. However, the contents of the real filestore's particular representations of these files may vary. For example, some systems will use escape sequences, different coded character sets, record delimiters, compaction flags, etc. in a different manner to store files on their system. If a tester compares the real filestores, the tester must take into account how their system represents the virtual files. To inspect a file's contents, the tester can:

1. Display or dump the contents of the files and manually compare the file contents.

2. Compare the two files using utilities (e.g., Unix diff command).

3. Understanding how the file is generated, write a program to analyze the received contents of the actual file to see if it contains what was expected. This allows testers not to have to store large files on their systems.

4. Any other method.

In some instances, the pass condition will specify that the responder must verify that a test case has successfully passed. 


\subsection{Test Files}

The contents of the test files are defined in section 3. Each test file is identified by its filename, document type, and file contents. The minimum length of a filename supported by all FTAM systems is eight characters. As such, the names of the test files used by the test cases may seem somewhat cryptic. However, the name of a test file contains valuable information. The naming convention for a test filename follows.

The first character identifies the location of the test file. Values for the first character of a test file can be:

$\mathrm{R} \quad$ - Responder: file is located on the responder's virtual filestore.

I - Initiator: file is located on the initiator's virtual filestore.

A - Actual: file is located on the initiator's virtual filestore. This file contains the actual contents received from performing a read operation on a remote file.

The second component identifies the document type of the test file. For limited file management and enhanced file management tests, the second component identifies which management attribute is being tested. Values for the second component of a test file can be:

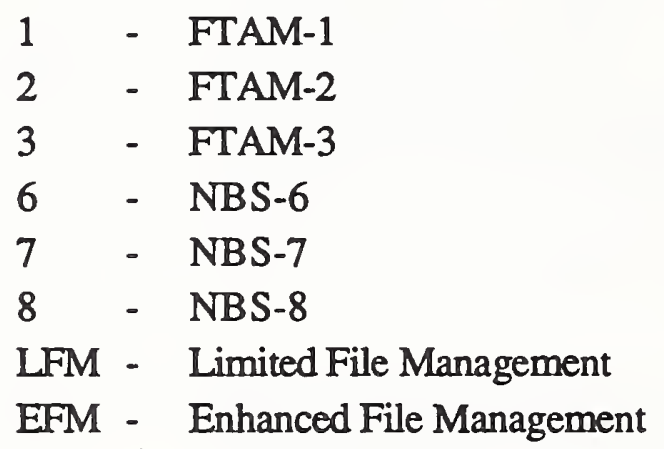

The third component identifies the type of action for which the test file is being used. This component is not used for naming management attribute test files. Values for the third component of a test file can be:

$$
\begin{array}{ll}
\text { R } & \text { - } \\
\text { Wead } & \text { - } \\
\text { Rrite } \\
\text { - } & \text { Multiple Reads } \\
\text { WW - } & \text { Multiple Writes } \\
\text { RW - } & \text { Multiple Reads and Writes }
\end{array}
$$


Files identified by the single characters ' $R$ ' and ' $W$ ' are used by the transfer and access service class tests. Files identified by "RR", "WW", and "RW" are used by the access service class tests.

The last component of a test file identifies the test case number.

As an example, the test file R1R1 states that this file resides on the responder's virtual filestore (the first ' $R$ '), is used to test an FTAM-1 document type (the first ' 1 '), is a file that is read by the initiator (the second ' $R$ '), and is the first test in the test group (the second ' 1 '). Given the name of a test file, one can deduce the test case that uses the file. In our example, file R1R1 is used by the test named FTAM1-R-1. Notice that the last three non-hyphen characters of the test name match the last three characters of the test filename.

\section{$* * * * *$ \\ NOTE: \\ ALL TEST FILES USED BY A TEST CASE MUST EXIST PRIOR TO RUNNING THE TEST CASE, UNLESS OTHERWISE NOTED. *****}

\subsection{Connections}

The ability to establish a connection is basic to the operation of all of the FTAM tests, therefore a test to explicitly exercise connection establishment is not proposed. The FTAM functional units, service classes, attribute groups and contents types will be given as required to parameterize the channel for a particular test group. (See Appendix B.) If the required connection parameters for a test can not be provided, the test fails. There is no dependency on the connection state between tests.

A single connection can be used to run one or more test cases if the required connection parameters for each test are supported. Thus, there is no requirement that a new connection be made in order to run each test case.

Some implementations may not provide to an end user the service of connection establishment outside of the context of a file operation. Those implementations which do not perform a simple connection establishment must establish connections prior to any file operations, and therefore their ability to establish a connection will have been tested if they pass the required set of tests. 


\subsection{Test Suites}

The organization of this document defines one set of FTAM interoperability tests that may be grouped differently to satisfy the testing requirements of various organizations.

A test suite specifies the service elements that define a complete group of functions to be tested. For each test suite, the required connection parameters and set of test cases that must be passed need to be clearly stated.

In defining the FTAM interoperability tests, the goals were to write a minimum number of test cases that provide the maximum test coverage in an implementation independent manner. A minimum number of files should be required to exist before testing begins. It is desirable to allow the test cases to run without operator intervention. This will require leaving behind files that are examined either mechanically or manually at the conclusion of testing. There should be no negative or unpredictable side effects produced by running a test suite one or more times on the same files in a directory. This may require having a set up procedure which is run before any testing begins to remove all unwanted files. 


\section{FTAM Interoperability Tests}

\subsection{FTAM-1 Test Cases}

\section{Transfer Service Class Tests}

Name: $\quad$ FTAM1-R-1

Purpose: $\quad$ Read an FTAM-1 file containing IA5 character strings.

Procedure: $\quad$ Read the complete file R1R1 and store the received contents into file A1R1.

Pass Condition: The initiator verifies that the contents of file A1R1 are identical to the contents defined for file R1R1.

Name:

FTAM1-R-2

Purpose:

Read an FTAM-1 file that contains ISO 8859-1 character strings.

Procedure:

Read the complete file $\mathbf{R} 1 \mathbf{R} 2$ and store the received contents into file A1R2.

Pass Condition: The initiator verifies that the contents of file A1R2 are identical to the contents defined for file R1R2. 
Name:

Purpose:

Procedure:

Pass Condition:
FTAM1-R-3

Read an FTAM-2 file as an FTAM-1 file. Tests for structural simplification, character relaxation, and string length relaxation of an FTAM-2 file.

If the responder supports the FTAM-2 document type, read the complete file $\mathbf{R} 2 \mathbf{R}$ and store the received contents into file A1R3.

The initiator verifies that the contents of file A1R3 contains the same sequence of data values as would result from accessing the structured text file in access context UA. The initiator verifies that the characters "carriage return" and "line feed" were added to the end of each string in the virtual file. The resultant virtual file is a single FADU whose contents contains:
10 'O' characters, $\mathrm{CR}, \mathrm{LF}$, 20 'S' characters, CR, LF, 30 'I' characters, $C R, L F$, 40 'F' characters, CR, LF, 50 ' $\mathrm{T}$ ' characters, $\mathrm{CR}, \mathrm{LF}$, 60 'A' characters, CR, LF, 70 ' $\mathrm{M}$ ' characters, CR, LF, 60 'T' characters, CR, LF, 50 'E' characters, $C R, L F$, 40 'S' characters, CR, LF, 30 'T' characters, CR, LF, and 20 'S' characters, CR, LF.

This test is only required if the responder supports the FTAM-2 document type.

\section{Name:}

FTAM1-W-1

Purpose:

Procedure: Replace an FTAM-1 file containing IA5 character strings.

Pass Condition: The responder verifies that the contents of file R1W1 are identical to the contents defined for file IIW1.

Name:

FTAM1-W-2

Purpose:

Procedure: Replace an FTAM-1 file containing ISO 8859-1 character strings.

Pass Condition: The responder verifies that the contents of file R1W2 are identical to the contents defined for file IIW2. 
Name:

Purpose:

Procedure:

Pass Condition:
FTAM1-W-3

Extend an FTAM-1 file containing IA5 character strings.

Extend file R1W3 with the contents of file IIW3.

The responder verifies that the contents of file $R \mathbf{R} \mathbf{W} 3$ are identical to the contents defined by concatenating file IIW 3 to the end of the original file R1W3.

Name:

FTAM1-W-4

Purpose:

Procedure:

Pass Condition:
Extend an FTAM-1 file containing ISO 8859-1 character strings.

Extend file R1W4 with the contents of file I1W4.

The responder verifies that the contents of file R1W4 are identical to the contents defined by concatenating file IIW4 to the end of the original file R1W4.

\section{Access Service Class Tests}

Name: $\quad$ FTAM1-WW-1

Purpose: $\quad$ Erase an FTAM-1 file.

Procedure: $\quad$ Erase file R1WW1.

Pass Condition: The responder verifies that file R1WW1 only contains a root node with an empty data unit. 


\subsection{FTAM-2 Test Cases}

The access context used by the FTAM-2 test cases is Flat All Data Units Access Context (FA).

Transfer Service Class Tests

Name:

FTAM2-R-1

Purpose:

Read the "begin" FADU (the whole file) in an FTAM-2 file.

Procedure:

Read the "begin" FADU in file $\mathbf{R} 2 \mathbf{R}$ and store the received contents into A2R1.

Pass Condition: The initiator verifies that the contents of file A2R1 are identical to the contents defined for file $\mathbf{R} 2 \mathbf{R}$.

Name:

\section{FTAM2-W-1}

Purpose:

Insert an FADU at the end of an FTAM-2 file.

Procedure: Insert an FADU at the end of file R2W1. The data unit contents contains 80 'B' characters.

Pass Condition: The responder verifies that 80 ' $\mathrm{B}$ ' characters were inserted at the end of file R2W1. 


\section{Access Service Class Tests}

Name:

Purpose:

Procedure:
FTAM2-RR-1

Perform multiple reads of an FTAM-2 file.

The following actions operate on file $\mathbf{R} 2 \mathbf{R}$. The received contents of these operations are stored into file A2RR1. The actions are:

1. Locate "next" FADU.

2. Read "next" FADU.

3. Read "next" FADU.

4. Locate "first" FADU.

5. Read "next" FADU.

6. Read "first" FADU.

7. Read "begin" FADU.

Pass Condition: The initiator verifies that file A2RR1 contains:

20 'S' characters,

30 ' $\mathrm{I}$ ' characters,

20 'S' characters,

10 'O' characters,

10 'O' characters,

20 'S' characters,

30 'I' characters,

40 ' $\mathrm{F}$ ' characters,

50 ' $\mathrm{T}$ ' characters,

60 'A' characters,

70 ' $\mathrm{M}$ ' characters,

60 ' $\mathrm{T}$ ' characters,

50 'E' characters,

40 'S' characters,

30 ' $\mathrm{T}$ ' characters, and

20 'S' characters. 
Name:

FTAM2-WW-1

Purpose:

Perform multiple writes to an FTAM-2 file.

Procedure:

The following actions operate on file R2WW1. The actions are:

1. Insert an FADU that contains $60^{\prime} A$ ' characters.

2. Insert an FADU that contains 80 ' $\mathrm{B}$ ' characters.

3. Insert an FADU that contains $40^{\prime} \mathrm{C}$ ' characters.

Pass Condition: The responder verifies that the contents of file R2WW1 are identical to the contents of file $\mathbf{R} 2 \mathbf{R}$ followed by 60 'A' characters, 80 'B' characters, and 40 'C' characters.

Name:

FTAM2-WW-2

Purpose:

Erase an FTAM-2 file.

Procedure:

Erase "begin" FADU of file R2WW2.

Pass Condition: The responder verifies that file R2WW2 only contains a root node with no data units. 
Name:

Purpose:

Procedure:

\section{FTAM2-RW-1}

Perform multiple reads and writes to an FTAM-2 file.

The following actions operate on file R2RW1. The received contents of these operations are stored into file A2RW1. The actions are:

1. Insert an FADU that contains $80^{\prime}$ ' $\mathrm{U}$ ' characters.

2. Insert an FADU that contains $80^{\prime}$ ' $\mathrm{C}$ ' characters.

3. Locate "begin" FADU.

4. Read "next" FADU.

5. Locate "next" FADU.

6. Read "next" FADU.

7. Locate "first" FADU.

8. Read "next" FADU.

9. Insert an FADU that contains 80 ' $\mathrm{L}$ ' characters.

10. Insert an FADU that contains $80^{\prime} \mathrm{A}$ ' characters.

11. Read "begin" FADU.

Pass Condition: The initiator verifies that the contents of file A2RW1 contains:

10 'O' characters,

30 'T' characters,

20 'S' characters,

10 'O' characters,

20 'S' characters,

30 ' $\mathrm{T}$ ' characters,

40 ' $\mathrm{F}$ ' characters,

50 ' $\mathrm{T}$ ' characters,

60 'A' characters,

70 ' $\mathrm{M}$ ' characters,

60 ' $\mathrm{T}$ ' characters,

50 'E' characters,

40 ' $S$ ' characters,

30 ' $\mathrm{T}$ ' characters,

20 'S' characters,

80 'U' characters,

80 'C' characters,

80 ' $\mathrm{L}$ ' characters, and

80 ' $\mathrm{A}$ ' characters. 


\subsection{FTAM-3 Test Cases}

\section{Transfer Service Class Tests}

Name: $\quad$ FTAM3-R-1

Purpose: $\quad$ Read an FTAM-3 file.

Procedure: $\quad$ Read file R3R1 and store its contents into file A3R1.

Pass Condition: The initiator verifies that the contents of file A3R1 are identical to the contents defined for file R3R1.

Name: $\quad$ FTAM3-R-2

Purpose: $\quad$ Read a large FTAM-3 file.

Procedure: $\quad$ Read file R3R2 and store its contents into file A3R2.

Pass Condition: The initiator verifies that the contents of file A3R2 are identical to the contents defined for file R3R2.

Name:

FTAM3-R-3

Purpose: $\quad$ Read a file whose filename is eight characters in length and contains numeric values.

Procedure: $\quad$ Read file R1234567 and store its contents into file A1234567.

Pass Condition: The initiator verifies that the contents of file A1234567 are identical to the contents defined for file R3R1.

Name: $\quad$ FTAM3-R-4

Purpose: $\quad$ Attempt to read a file that does not exist.

Procedure: $\quad$ Read file RXYZ and store its contents into file AXYZ. The file RXYZ must not exist on the responder's filestore.

Pass Condition: The initiator verifies that an error indicating that the file does not exist is returned.

Name:

FTAM3-R-5

Purpose:

Procedure:

Check error handling when an invalid filename format is used.

Attempt to read a file using an invalid filename format for the test partners file system. This may include case sensitivity on some systems. Details will need to be obtained from the test partner.

Pass Condition: The initiator verifies that a suitable error message is returned. This can not be better defined as it will be system specific. The responder verifies that no adverse effects result from this request. 
Name:

Purpose:

Procedure:

Pass Condition: The initiator and responder check that there is no adverse effect on their FTAM system. Recovery is not necessary, just graceful handling of the situation.

Name:

FTAM3-R-7

Purpose:

Procedure:

Permitted action prevents reading file.

Pass Condition: The initiator verifies that an error indicating that the file does not allow its contents to be read is returned.

Name:

Purpose:

Procedure:

Pass Condition:

Name:

Purpose:

Procedure:

Pass Conditions:

Name:

Purpose:

Procedure:

Pass Condition:

Name:

Purpose:

Procedure:

Pass Condition:
FTAM3-W-1

Replace an FTAM-3 file.

Replace file R3W1 with file I3W1.

The responder verifies that the contents of file R3W1 are identical to the contents defined for file I3W1.

Replace a small FTAM-3 file with a large FTAM-3 file.

Replace file R3W2 with file $\mathbf{1 3}$ W2.

The responder verifies that the contents of file R3W2 are identical to the contents defined for file I3W2.

FTAM3-W-3

Replace a large FTAM-3 file with a small FTAM-3 file. Replace file R3W3 with file I3W3.

The responder verifies that the contents of file $\mathbf{R} 3 \mathbf{W} 3$ are identical to the contents defined for file $\mathbf{I} \mathbf{W} \mathbf{3}$. The responder verifies the filesize attribute and/or verifies that no extra information exists.

FTAM3-W-4

Extend file R3W4 with the contents of file I3W4.

The responder verifies that the contents of file R3W4 are identical to the contents defined by concatenating file I3W 4 to the end of the original file R3W4.
FTAM3-W-2

Extend an FTAM-3 file. 
Name:

Purpose:

Procedure:

Pass Condition:
FTAM3-W-5

Permitted actions allow extend, but not replace.

Replace file R3W5 with the contents of file I3W5. Extend file R3W5 with the contents of file I3W5.

The initiator verifies that an error indicating that the file does not allow its contents to be replaced is returned. The responder verifies that the contents of file R3W5 are identical to the contents defined by concatenating file I3W5 to the end of the original file R3W5.

\section{Access Service Class Tests}

Name: $\quad$ FTAM3-WW-1

Purpose: $\quad$ Erase an FTAM-3 file.

Procedure: $\quad$ Erase file R3WW1.

Pass Condition: The responder verifies that file R3WW1 only contains a root node with an empty data unit. 


\subsection{NBS-6 Test Cases}

The access context used by the NBS- 6 test cases is Flat All Data Units Access Context (FA).

\section{Transfer Service Class Tests}

Name:

Purpose:

Pass Condition:
Procedure:

\section{NBS6-R-1}

Read "begin" FADU in an NBS-6 file.

Read "begin" FADU in file R6R and store the result in file A6R1.

The initiator verifies that the contents of file A6R1 are identical to the contents defined for file R6R.

Name:

NBS6-R-2

Purpose:

Read "begin" FADU in an NBS-6 file.

Procedure: Read "begin" FADU in file R6R2 and store the result in file A6R2.

Pass Condition: The initiator verifies that the contents of file A6R2 are identical to the contents defined for file R6R2.

Name:

NBS6-W-1

Purpose:

Insert an FADU at the "end" of an NBS-6 file.

Procedure: Insert an FADU at the end of file R6W1. The data elements contain the following values: "Warsaw", "Poland", 294, '100100110'B, '126'H, 22.0, "inches", and FALSE.

Pass Condition: The responder verifies that the above data unit was inserted at the end of file R6W1.

Name:

NBS6-W-2

Purpose: Insert an FADU at the "end" of an NBS-6 file.

Procedure: Insert an FADU at the end of file R6W2. The data elements contain the following values: "October 31, 1992 5:35 p.m.", "19921031173500.0", null, and "9210311735Z".

Pass Condition: The responder verifies that the above data unit was inserted at the end of file R6W2. 
NBS-6 Test Cases

\section{Access Service Class Tests}

Name: $\quad$ NBS6-RR-1

Purpose: $\quad$ Perform multiple reads of an NBS-6 file.

Procedure: $\quad$ The following actions operate on file R6R. The received contents of these operations are stored into file A6RR1. The actions are:

1. Locate "next" FADU.

2. Read "next" FADU.

3. Read "next" FADU.

4. Locate "first" FADU.

5. Read "next" FADU.

6. Read "first" FADU.

7. Read "begin" FADU.

Pass Condition: The initiator verifies that file A6RR1 contains:

\begin{tabular}{|c|c|c|c|c|c|c|c|}
\hline "London" & "England" & 149 & ' 10010101 'B & '95'H & 22.9 & "inches" & FALSE \\
\hline "Manila" & "Philippines" & 49 & '110001'B & '31'H & 82.0 & "inches" & TRUE \\
\hline "London" & "England" & 149 & ' 10010101 'B & '95'H & 22.9 & "inches" & FALSE \\
\hline "Berlin" & "Germany" & 187 & ' 10111011 'B & ' 66 'H & 23.1 & "inches" & ALSE \\
\hline "Berlin" & "Germany" & 187 & $' 10111011^{\prime} \mathrm{B}$ & ' $66^{\prime} \mathrm{H}$ & 23.1 & "inches" & FALSE \\
\hline "London" & "England" & 149 & ' 10010101 'B & '95'H & 22.9 & "inches" & FALSE \\
\hline "Manila" & "Philippines" & 49 & ' 110001 'B & 31 'H & 82.0 & "inches" & TRUE \\
\hline "Paris" & "France" & 164 & '10100100'B & 'A4'H & 22.3 & "inches" & FALSE \\
\hline "Sydney" & "Australia" & 62 & ' $111110^{\prime} \mathrm{B}$ & '3E'H & 46.5 & "inches" & FALS \\
\hline "Tokyo" & "Japan" & 19 & '10011'B & 13 'H & 61.6 & "inches" & TRUE \\
\hline
\end{tabular}


Name:

Purpose:

Procedure:
NBS6-WW-1

Perform multiple writes to an NBS-6 file.

The following actions operate on file R6WW1. The actions are:

1. Insert an FADU that contains: "Athens", "Greece", 351, '101011111'B, '15F'H, 15.8, "inches", and FALSE.

2. Insert an FADU that contains: "Rome", "Italy", 377, '101111001'B, '179'H, 29.5, "inches", and FALSE

3. Insert an FADU that contains: "Bangkok", "Thailand", 53, '110101'B, '35'H, 57.8, "inches", and TRUE.

Pass Condition: The responder verifies that the contents of file R6WW1 is identical to the contents of file R6R followed by:

$\begin{array}{llrrrrrl}\text { "Athens" } & \text { "Greece" } & 351 & \text { '101011111'B } & \text { '15F'H } & 15.8 & \text { "inches" } & \text { FALSE } \\ \text { "Rome" } & \text { "Italy" } & 377 & \text { '101111001'B } & \text { '179'H } & 29.5 & \text { "inches" } & \text { FALSE } \\ \text { "Bangkok" } & \text { "Thailand" } & 53 & ' 110101 \text { 'B } & \text { '35'H } & 57.8 & \text { "inches" } & \text { TRUE }\end{array}$

Name:

NBS6-WW-2

Purpose:

Erase an NBS-6 file.

Procedure:

Erase "begin" FADU of file R6WW2.

Pass Condition: The responder verifies that file R6WW2 only contains a root node with an empty data unit. 
Name:

Purpose:

Procedure:

\section{NBS6-RW-1}

Perform multiple reads and writes to an NBS-6 file.

The following actions operate on file R6RW1. The received contents of these operations are stored into file A6RW1. The actions are:

1. Insert an FADU that contains: "Oslo", "Norway", 308, '100110100'B, '134'H, 26.9, "inches", and FALSE.

2. Insert an FADU that contains: "Dublin", "Ireland", 155, '10011011'B, '96'H, 29.7, "inches", and FALSE.

3. Locate "first" FADU.

4. Read "next" FADU.

5. Locate "begin" FADU.

6. Read "next" FADU.

7. Insert an FADU that contains: "Cairo", "Egypt", 381, '101111101'B, '17D'H, 1.1, "inches", and FALSE.

8. Read "begin" FADU.

Pass Condition: The initiator verifies that the contents of file A6RW1 contains:

\begin{tabular}{|c|c|c|c|c|c|c|c|}
\hline "London" & "England" & 149 & ' 10010101 'B & '95'H & 22.9 & "inches" & FALSE \\
\hline "Berlin" & "Germany" & 187 & '10111011'B & '66'H & 23.1 & "inches" & FALSE \\
\hline "Berlin" & "Germany" & 187 & '10111011'B & '66'H & 23.1 & "inches" & FALSE \\
\hline "London" & "England" & 149 & '10010101'B & '95'H & 22.9 & "inches" & FALSE \\
\hline "Manila" & "Philippines" & 49 & '110001'B & ' 31 'H & 82.0 & "inches" & TRUE \\
\hline "Paris" & "France" & 164 & '10100100'B & 'A4'H & 22.3 & "inches" & FALSE \\
\hline "Sydney" & "Australia" & 62 & '111110'B & '3E'H & 46.5 & "inches" & FALS \\
\hline "Tokyo" & "Japan" & 19 & ' 10011 'B & ' 13 'H & 61.6 & "inches" & TRUF \\
\hline "Oslo" & "Norway" & 308 & '100110100'B & '134'H & 26.9 & "inches" & FALS \\
\hline "Dublin" & "Ireland" & 155 & '10011011'B & '96'H & 29.7 & "inches" & FALS \\
\hline "Cairo" & "Egypt" & 381 & '101111101'B & '17D'H & 1.1 & "inches" & FALs \\
\hline
\end{tabular}




\subsection{NBS-7 Test Cases}

The access context used by the NBS-7 test cases is Flat All Data Units Access Context (FA).

\section{Transfer Service Class Tests}

Name: $\quad$ NBS7-R-1

Purpose: $\quad$ Read the "begin" FADU in an NBS-7 file.

Procedure: $\quad$ Read the "begin" FADU (the whole file) in file R7R store the received contents into file A7R1.

Pass Condition: The initiator verifies that the contents of file A7R1 is identical to the contents defined for file $\mathbf{R} 7 \mathbf{R}$.

Name: $\quad$ NBS7-R-2

Purpose: $\quad$ Read the "first" FADU in an NBS-7 file.

Procedure: $\quad$ Read the "first" FADU in file R7R.

Pass Condition: The initiator verifies that the following data unit is received: 100, "9.83s", "Ben Johnson", "Canada", "19870830151500.0", and "8708301515Z".

Name: $\quad$ NBS7-R-3

Purpose: $\quad$ Read the "last" FADU in an NBS-7 file.

Procedure: $\quad$ Read the "last" FADU in file R7R.

Pass Condition: The initiator verifies that the following data unit is received: $3000, " 7 \mathrm{~m}$, 32.1s", "Henry Rono", "Kenya", "19780727181800.0", and "7807271818Z".

Name: $\quad$ NBS7-R-4

Purpose: . Read the "current" FADU in an NBS-7 file.

Procedure: $\quad$ Read "current" FADU in file R7R and store the received contents into file A7R4.

Pass Condition: The initiator verifies that the contents of file A7R4 is identical to the contents defined for file $\mathbf{R 7 R}$.

Name: $\quad$ NBS7-R-5

Purpose: $\quad$ Read the "next" FADU in an NBS-7 file.

Procedure: $\quad$ Read "next" FADU in file R7R.

Pass Condition: The initiator verifies that the following data unit is received: 100, "9.83s", "Ben Johnson", "Canada", "19870830151500.0", and "8708301515Z". 
Name:

Purpose:

Procedure:

Pass Condition:

Name:

Purpose:

Procedure:

Pass Condition:

Name:

Purpose:

Procedure:

Pass Condition:

Name:

Purpose:

Procedure:

Pass Condition: The initiator verifies that the contents of file A7R9 is identical to the contents defined for file R7R9.
Name:

Purpose:

Procedure:

Pass Condition: The responder verifies that the above data unit was inserted at the end of file

R7W1.

NBS7-W-1

Insert an FADU at the "end" of an NBS-7 file.

Insert a new FADU at the "end" of file R7W1. The data unit contents contains: 400, "43.29s", "Butch Reynolds", "United States", "19880822092500.0", and "8808220925Z". 
Name:

Purpose:

Procedure:

Pass Condition:

NBS7-W-2

Insert an FADU at the end of an NBS-7 file whose position is identified by traversal number.

Insert a new FADU into file $\mathbf{R} 7$ W2 2 after the FADU whose traversal number is 50. The data unit contents contains: 100, "10.49s", "Florence Griffith-Joyner", "United States", "19880915012300.0", and "8809150123Z".

The responder verifies that the above data unit was inserted at the end of file R7W2.

Name: $\quad$ NBS7-W-3

Purpose: $\quad$ Replace the "first" FADU in an NBS-7 file.

Procedure: $\quad$ Replace the "first" FADU in file R7W3 with a new data unit that contains: 400, "43.29s", "Butch Reynolds", "United States", "19880822092500.0", and "8808220925Z".

Pass Condition: The responder verifies that file R7W 3 contains:

$\begin{array}{llllll}400 & \text { "43.29s" } & \text { "Butch Reynolds" "United States" } & \text { "19880822092500.0" } & \text { "8808220925Z" } \\ 200 & \text { "19.72s" } & \text { "Pietro Mennea" } & \text { "Italy" } & \text { "19790917161600.0" } & \text { "7909171616Z" } \\ 400 & \text { "47.60s" } & \text { "Marita Koch" } & \text { "East Germany" } & \text { "19851006171700.0" } & \text { "8510061717Z" } \\ 1000 & \text { "2m, 12.18s" } & \text { "Sebastian Coe" } & \text { "Great Britain" } & \text { "19810711181800.0" } & \text { "8107111818Z" } \\ 3000 & \text { "7m, 32.1s" } & \text { "Henry Rono" } & \text { "Kenya" } & \text { "19780727191900.0" } & \text { "7807271919Z" }\end{array}$

Name: $\quad$ NBS7-W-4

Purpose: $\quad$ Replace the "next" FADU in an NBS-7 file.

Procedure: $\quad$ Replace the "next" FADU in file R7W5 with a new data unit that contains: 400, "43.29s", "Butch Reynolds", "United States", "19880822092500.0", and "8808220925Z".

Pass Condition: See pass condition for test case NBS7-W-5. 


\section{Name: $\quad$ NBS7-W-5}

Purpose: $\quad$ Replace the "last" FADU in an NBS-7 file.

Procedure: $\quad$ Replace the "last" FADU in file R7W5 with a new data unit that contains 1500, "3m, 29.46s", "Said Aouita", "Morocco", "19850823151500.0", and "8508231515Z".

Pass Condition: The responder verifies that file R7W5 contains:

$\begin{array}{llllll}400 & \text { "43.29s" } & \text { "Butch Reynolds" } & \text { "United States" } & \text { "19880822092500.0" } & \text { "8808220925Z" } \\ 200 & \text { "19.72s" } & \text { "Pietro Mennea" } & \text { "Italy" } & \text { "19790917161600.0" } & \text { "7909171616Z" } \\ 400 & \text { "47.60s" } & \text { "Marita Koch" } & \text { "East Germany" } & \text { "19851006171700.0" } & \text { "8510061717Z" } \\ 1000 & \text { "2m, 12.18s" } & \text { "Sebastian Coe" } & \text { "Great Britain" } & \text { "19810711181800.0" } & \text { "8107111818Z" } \\ 1500 & \text { "3m, 29.46s" } & \text { "Said Aouita" } & \text { "Morocco" } & \text { "19850823151500.0" } & \text { "8508231515Z". }\end{array}$

The resultant file is from running test cases NBS7-W-4 through NBS7-W-5 in any order.

Name:

Purpose:

Pass Condition:
Procedure:

\section{NBS7-W-6}

Replace the "previous" FADU in an NBS-7 file.

Replace the "previous" FADU in file R7W6 with a new data unit that contains: 400, "43.29s", "Butch Reynolds", "United States", "19880822092500.0", and "8808220925Z". This action should fail.

The responder verifies that the contents of file R7W6 are identical to the contents defined for file $\mathbf{R} 7 \mathbf{R}$.

Name:

\section{NBS7-W-7}

Purpose:

Procedure:

Replace the first FADU identified by traversal number.

Replace the first FADU identified by traversal number 1 in file R7W10 with a new data unit that contains: 400, "43.29s", "Butch Reynolds", "United States", "19880822092500.0", and "8808220925Z".

Pass Condition: See pass condition for test case NBS7-W-10.

Name:

NBS7-W-8

Purpose:

Replace the "current" FADU in an NBS-7 file.

Procedure:

Pass Condition: See pass condition for test case NBS7-W-10. 
Name:

NBS7-W-9

Purpose:

Replace an FADU identified by traversal number.

Procedure:

Replace the FADU identified by traversal number 2 in file R7W10 with a new data unit that contains: 1500, "3m, 29.46s", "Said Aouita", "Morocco", "19850823151500.0", and "8508231515Z".

Pass Condition: See pass condition for test case NBS7-W-10.

Name:

Purpose:

Procedure:
NBS7-W-10

Replace the last FADU identified by traversal number.

Replace the FADU identified by traversal number 5 in file R7W10 with a new data unit contains: 2000, "4m, 50.81s", "Said Aouita", "Morocco", "19870716202000.0", and "8707162020Z".

Pass Condition: The responder verifies that file R7W10 contains:

$\begin{array}{llllll}400 & \text { "43.29s" } & \text { "Butch Reynolds" "United States" } & \text { "19880822092500.0" } & \text { "8808220925Z" } \\ 1500 & \text { "3m, 29.46s" } & \text { "Said Aouita" } & \text { "Morocco" } & \text { "19850823151500.0" } & \text { "8508231515Z" } \\ 400 & \text { "47.60s" } & \text { "Marita Koch" } & \text { "East Germany" } & \text { "19851006171700.0" } & \text { "8510061717Z" } \\ 1000 & \text { "2m, 12.18s" } & \text { "Sebastian Coe" } & \text { "Great Britain" } & \text { "19810711181800.0" } & \text { "8107111818Z" } \\ 2000 & \text { "4m, 50.81s" } & \text { "Said Aouita" } & \text { "Morocco" } & \text { "19870716202000.0" } & \text { "8707162020Z" }\end{array}$

The resultant file is from running test cases NBS7-W-7 through NBS7-W10 in any order.

Name:

NBS7-W-11

Purpose:

Replace the "begin" FADU in an NBS-7 file.

Procedure:

Replace the "begin" FADU (the whole file) in file R7W11 with:

400 "47.60s" "Marita Koch" "East Germany" "19851006171700.0" 400 "43.29s" "Butch Reynolds" "United States" "19880822092500.0" 1000 "2m, 12.18s" "Sebastian Coe" "Great Britain" "19810711181800.0" "8510061717Z" "8808220925Z" "8107111818Z"

Pass Condition: The responder verifies that file R7W11 contains:

$\begin{array}{llllll}400 & \text { "47.60s" } & \text { "Marita Koch" } & \text { "East Germany" } & \text { "19851006171700.0" } & \text { "8510061717Z" } \\ 400 & \text { "43.29s" } & \text { "Butch Reynolds" } & \text { "United States" } & \text { "19880822092500.0" } & \text { "8808220925Z" } \\ 1000 & \text { "2m, 12.18s" } & \text { "Sebastian Coe" } & \text { "Great Britain" } & \text { "19810711181800.0" } & \text { "8107111818Z" }\end{array}$


Name:

Purpose:

Procedure:

\section{Access Service Class Tests}

Name:

Purpose:

Procedure: FALSE. R7W12.
NBS7-W-12

Insert an FADU at the "end" of an NBS-7 file.

Insert a new FADU at the "end" of file R7W12. The data unit contents contains: "South America", 69, '1000101'B, '45'H, null, 11.9, 5.6 and

Pass Condition: The responder verifies that the above data unit was inserted at the end of file

1. Locate "end" FADU.

2. Read "previous" FADU.

3. Locate "first" FADU.

4. Read "current" FADU.

5. Locate "next" FADU.

6. Read "current" FADU.

7. Locate "next" FADU.

8. Locate "next" FADU.

9. Read "next" FADU.

10. Locate "last" FADU.

11. Read "current" FADU.

12. Locate "previous" FADU.

13. Read "current" FADU.

Pass Condition: The initiator verifies that the contents of file A7RR1 contains:

$\begin{array}{lll}\text { "Spanish" } & \text { null } & 320 \\ \text { "Arabic" } & \text { null } & 187 \\ \text { "English" } & \text { null } & 431 \\ \text { "German" } & \text { null } & 118 \\ \text { "Spanish" } & \text { null } & 320 \\ \text { "Russian" } & \text { null } & 289\end{array}$


Name: $\quad$ NBS7-RR-2

Purpose: $\quad$ Perform multiple reads of an NBS-7 file.

Procedure: The following actions operate on file R7RR1. The received contents of these operations are stored into file A7RR2. The actions are:

1. Locate FADU whose traversal number is 7.

2. Read "current" FADU.

3. Locate "previous" FADU.

4. Read "current" FADU.

5. Locate FADU whose traversal number is 1.

6. Read "current" FADU.

7. Locate "next" FADU.

8. Read "current" FADU.

9. Locate FADU whose traversal number is $\mathbf{1 2 .}$

10. Read "current" FADU.

11. Locate "current" FADU.

Pass Condition: The initiator verifies that the contents of file A7RR2 contains:

$\begin{array}{llr}\text { "Japanese" } & \text { null } & 124 \\ \text { "Italian" } & \text { null } & 63 \\ \text { "Arabic" } & \text { null } & 187 \\ \text { "English" } & \text { null } & 431 \\ \text { "Spanish" } & \text { null } & 320\end{array}$


Name:

Purpose:

Procedure:

\section{NBS7-WW-1}

Perform multiple writes to an NBS-7 file.

The following actions operate on file R7WW1. The actions are:

1. Insert an FADU that contains: Polish, null, 42.

2. Insert an FADU that contains: Tagalog, null, 33.

3. Insert an FADU that contains: Min, null, 45.

4. Locate "first" FADU.

5. Replace current FADU with an FADU that contains: Hebrew, null, 4 .

6. Locate "next" FADU.

7. Replace current FADU with an FADU that contains: Swati, null, 1.

8. Locate "last" FADU.

9. Replace current FADU with an FADU that contains: Swedish, null, 9.

10. Locate "previous" FADU.

11. Replace current FADU with an FADU that contains: Hindi, null, 325.

12. Locate FADU whose traversal number is 6.

13. Replace current FADU with an FADU that contains: Bengali, null, 178.

14. Locate FADU whose traversal number is $\mathbf{1 0 0 .}$

15. Insert an FADU that contains: Thai, null, 46 .

Pass Condition: The responder verifies that the contents of file R7WW1 contains:

$\begin{array}{lrr}\text { "Hebrew" } & \text { null } & 4 \\ \text { "Swati" } & \text { null } & 1 \\ \text { "Esperanto" } & \text { null } & 2 \\ \text { "French" } & \text { null } & 117 \\ \text { "German" } & \text { null } & 118 \\ \text { "Bengali" } & \text { null } & 178 \\ \text { "Japanese" } & \text { null } & 124 \\ \text { "Korean" } & \text { null } & 68 \\ \text { "Mandarin" } & \text { null } & 825 \\ \text { "Portuguese" } & \text { null } & 169 \\ \text { "Russian" } & \text { null } & 289 \\ \text { "Spanish" } & \text { null } & 320 \\ \text { "Polish" } & \text { null } & 42 \\ \text { "Hindi" } & \text { null } & 325 \\ \text { "Swedish" } & \text { null } & 9 \\ \text { "Thai" } & \text { null } & 46\end{array}$


Name: $\quad$ NBS7-WW-2

Purpose:

Erase an NBS-7 file.

Procedure:

Erase "begin" FADU of file R7WW2.

Pass Condition: The responder verifies that file R7WW2 only contains a root node with an empty data unit.

Name:

NBS7-WW-3

Purpose:

Replace an entire NBS-7 file.

Procedure:

Locate "begin" of file R7WW3. Replace file R7WW3 with:

$\begin{array}{llr}\text { "Japanese" } & \text { null } & 124 \\ \text { "Korean" } & \text { null } & 68 \\ \text { "Mandarin" } & \text { null } & 825\end{array}$

Pass Condition: The responder verifies that file R7WW3 contains:

$\begin{array}{llr}\text { "Japanese" } & \text { null } & 124 \\ \text { "Korean" } & \text { null } & 68 \\ \text { "Mandarin" } & \text { null } & 825\end{array}$


Name:

Purpose:

Procedure:
NBS7-RW-1

Perform multiple reads and writes to an NBS-7 file.

The following actions operate on file R7RW1. The received contents of these operations are stored into file A7RW1. The actions are:

1. Locate FADU whose traversal number is 7 .

2. Read "current" FADU.

3. Insert an FADU that contains: Finnish, null, 5.

4. Insert an FADU that contains: Greek, null, 11.

5. Read "previous" FADU.

6. Locate "first" FADU.

7. Read "current" FADU.

8. Insert an FADU that contains: Zulu, null, 7.

9. Insert an FADU that contains: Rundi, null, 5 .

10. Locate "previous" FADU.

11. Read "previous" FADU.

12. Read "begin" FADU.

Pass Condition: The initiator verifies that the contents of file A7RW1 contains:

$\begin{array}{llr}\text { "Japanese" } & \text { null } & 124 \\ \text { "Greek" } & \text { null } & 11 \\ \text { "Arabic" } & \text { null } & 187 \\ \text { "Zulu" } & \text { null } & 7 \\ \text { "Arabic" } & \text { null } & 187 \\ \text { "English" } & \text { null } & 431 \\ \text { "Esperanto" } & \text { null } & 2 \\ \text { "French" } & \text { null } & 117 \\ \text { "German" } & \text { null } & 118 \\ \text { "Italian" } & \text { null } & 63 \\ \text { "Japanese" } & \text { null } & 124 \\ \text { "Korean" } & \text { null } & 68 \\ \text { "Mandarin" } & \text { null } & 825 \\ \text { "Portuguese" } & \text { null } & 169 \\ \text { "Russian" } & \text { null } & 289 \\ \text { "Spanish" } & \text { null } & 320 \\ \text { "Finish" } & \text { null } & 5 \\ \text { "Greek" } & \text { null } & 11 \\ \text { "Zulu" } & \text { null } & 7 \\ \text { "Rundi" } & \text { null } & 5\end{array}$


Name:

Purpose:

Procedure:
NBS7-RW-2

Create holes in an NBS-7 file.

The following actions operate on file R7RW2. The received contents of these operations are stored into file A7RW2. The actions are:

1. Locate FADU whose traversal number is 3.

2. Replace current FADU with an FADU with a data unit of length 0 (or without a data unit).

3. Locate FADU whose traversal number is 8 .

4. Replace current FADU with an FADU with a data unit of length 0 (or without a data unit).

5. Locate FADU whose traversal number is 12.

6. Replace current FADU with an FADU with a data unit of length 0 (or without a data unit).

7. Read "begin" FADU.

Pass Condition: The initiator verifies that the contents of file A7RW2 contains:

$\begin{array}{llr}\text { "Arabic" } & \text { null } & 187 \\ \text { "English" } & \text { null } & 431 \\ \text { "French" } & \text { null } & 117 \\ \text { "German" } & \text { null } & 118 \\ \text { "Italian" } & \text { null } & 63 \\ \text { "Japanese" } & \text { null } & 124 \\ \text { "Mandarin" } & \text { null } & 825 \\ \text { "Portuguese" } & \text { null } & 169 \\ \text { "Russian" } & \text { null } & 289\end{array}$


Name:

Purpose:

Procedure:
NBS7-RW-3

Fill holes in an NBS-7 file.

The following actions operate on file R7RW3. The received contents of these operations are stored into file A7RW3. The actions are:

1. Locate FADU whose traversal number is 3.

2. Replace current FADU with an FADU that contains: Nepali, null, 12.

3. Locate FADU whose traversal number is 7.

4. Replace "next" FADU with an FADU that contains: Persian, null, 31.

5. Read "begin" FADU.

Pass Condition: The initiator verifies that the contents of file A7RW3 contains:

$\begin{array}{llr}\text { "Arabic" } & \text { null } & 187 \\ \text { "English" } & \text { null } & 431 \\ \text { "Nepali" } & \text { null } & 12 \\ \text { "French" } & \text { null } & 117 \\ \text { "German" } & \text { null } & 118 \\ \text { "Italian" } & \text { null } & 63 \\ \text { "Japanese" } & \text { null } & 124 \\ \text { "Persian" } & \text { null } & 31 \\ \text { "Mandarin" } & \text { null } & 825 \\ \text { "Portuguese" } & \text { null } & 169 \\ \text { "Russian" } & \text { null } & 289\end{array}$




\subsection{NBS-8 Test Cases}

The access context used by the NBS-8 test cases is Flat All Data Units Access Context (FA).

\section{Transfer Service Class Tests}

Name:

Purpose:

Procedure:

Pass Condition:

Name:

Purpose:

Procedure:

Pass Condition:

Name:

Purpose:

Procedure:

Pass Condition:

Name:

Purpose:

Procedure:

Pass Condition:

Name:

Purpose:

Procedure:

Pass Condition:

Name:

Purpose:

Procedure:

Pass Condition:
NBS8-R-1

Read the "begin" FADU.

Read the "begin" FADU (the whole file) in file $\mathbf{R 8 R}$ and store the received contents into file A8R1.

The initiator verifies that the contents of file A8R1 are identical to the contents defined for file R8R.

NBS8-R-2

Read the "current" FADU.

Read "current" FADU in file R8R.

The initiator verifies that no data elements are received.

NBS8-R-3

Read the "next" FADU.

Read "next" FADU in R8R.

The initiator verifies that the following data elements are received: "U.S.", "9638", "10714", and 8682.

\section{NBS8-R-4}

Read the "previous" FADU.

Read "previous" FADU in file $\mathbf{R} 8 \mathbf{R}$.

The initiator verifies that no data elements are received.

\section{NBS8-R-5}

Read an FADU by its node sequence.

Read FADU "Sydney" in file R8R by its node name.

The initiator verifies that the following data elements are received: "Australia", "3396", "3708", and 10047.

\section{NBS8-R-6}

Read the first FADU by its node sequence.

Read FADU "Los Angeles" in file R8R by its node name.

The initiator verifies that the following data elements are received: "U.S.", "9638", "10714", and 8682. 
Name:

Purpose:

Pass Condition:
Procedure:

\section{NBS8-R-7}

Read the last FADU by its node sequence.

Read FADU "Tokyo-Yokahama" in file R8R by its node name.

The initiator verifies that the following data elements are received : "Japan", "25434", "29971", and 23356.

Name:

NBS8-R-8

Purpose:

Procedure:

Pass Condition:

Read the "begin" FADU (the whole file) in file R8R8 and store the received contents into file A8R8.

The initiator verifies that the contents of file $\mathbf{A 8 R 8}$ are identical to the contents defined for file R8R8.

Name:

NBS8-W-1

Purpose:

Insert a new FADU.

Procedure:

Insert a new FADU in file R8W4 identified as node "New York" and whose data elements contain: "U.S.", "14598", "14648", and 11458.

Pass Condition: See pass condition for test case NBS8-W-4.

Name:

NBS8-W-2

Purpose:

Insert a new FADU at the beginning.

Procedure:

Insert a new FADU in file R8W4 identified as node "Hong Kong" and whose data elements contain: "British Colony", "5415", "5956", and 270750.

Pass Condition: $\quad$ See pass condition for test case NBS8-W-4.

Name:

NBS8-W-3

Purpose:

Insert a new FADU at the end.

Procedure:

Insert a new FADU in file R8W4 identified as node "Toronto" and whose data elements contain: "Canada", "2972", "3296", and 19300.

Pass Condition: $\quad$ See pass condition for test case NBS8-W-4. 
Name:

Purpose:

Procedure:

\section{NBS8-W-4}

Insert two FADUs with the same FADU identifier.

Insert the following two FADUs into file R8W4: a new FADU identified as node "Moscow" and whose data elements contain "USSR", "9873", "11121", and 26050, and a new FADU which is also identified as node "Moscow" and whose data elements contain: "Soviet", "Union", "1234", and 100.

Pass Condition: The responder verifies that file $\mathbf{R} 8 \mathbf{W} \mathbf{4}$ contains:

Node Name
"Hong Kong"
"Los Angeles"
"Manchester"
"Mexico City"
"Moscow"
"Moscow"
"New York"
"Singapore"
"Sydney"
"Tokyo-Yokahama"
"Toronto"

$\begin{array}{lrrr}\text { Contents } & & & \\ \text { "British Colony" } & \text { "5415" } & \text { "5956" } & 270750 \\ \text { "U.S." } & \text { "9638" } & \text { "10714" } & 8682 \\ \text { "U.K." } & \text { "4151" } & \text { "3827" } & 11627 \\ \text { "Mexico" } & \text { "16900" } & \text { "27872" } & 32377 \\ \text { "USSR" } & \text { "9873" } & \text { "11121" } & 26050 \\ \text { "Soviet" } & \text { "Union" } & \text { "1234" } & 100 \\ \text { "U.S." } & \text { "14598" } & \text { "14648" } & 11458 \\ \text { "Singapore" } & \text { "2556" } & \text { "2913" } & 32769 \\ \text { "Australia" } & \text { "3396" } & \text { "3708" } & 10047 \\ \text { "Japan" } & \text { "25434" } & \text { "29971" } & 23356 \\ \text { "Canada" } & \text { "2972" } & \text { "3296" } & 19300\end{array}$

The resultant file is from running test cases NBS8-W-1 through NBS8-W-4 in any order. 
Name:

Purpose:
Procedure:

\section{NBS8-W-5}

Replace the "begin" FADU.

Replace the "begin" FADU of file R8W5 (the complete file) with a new file whose FADU node names are: "Bombay", "Cairo", "Lima", "Lima", and "Milan". The contents of this file contains the following data elements:

$\begin{array}{lrrr}\text { "India" } & \text { "10137" } & \text { "15357" } & 10670 \\ \text { "Egypt" } & \text { "8595" } & \text { "12500" } & 82644 \\ \text { "Peru" } & \text { "5447" } & \text { "9241" } & 45392 \\ \text { "Inca" } & \text { "Empire" } & \text { "Andes" } & 100 \\ \text { "Italy" } & \text { "4635" } & \text { "4839" } & 13474\end{array}$

Pass Condition: The responder verifies that file $\mathbf{R 8 W 5}$ contains:

\begin{tabular}{llrrr} 
Node Name & Contents & & & \\
\cline { 2 - 4 } & "India" & "10137" & "15357" & 10670 \\
"Cairo" & "Egypt" & "8595" & "12500" & 82644 \\
"Lima" & "Peru" & "5447" & "9241" & 45392 \\
"Lima" & "Inca" & "Empire" & "Andes" & 100 \\
"Milan" & "Italy" & "4635" & "4839" & 13474
\end{tabular}

Name: $\quad$ NBS8-W-6

Purpose: $\quad$ Replace "current" FADU.

Procedure: $\quad$ Replace the "current" FADU in file R8W6 with a new FADU identified as node "Sao Paolo" and whose data elements contain: "Brazil", "14910", "25354", and 33060.

Pass Condition: The responder verifies that file R8W6 contains:

\begin{tabular}{llrrr} 
Node Name & Contents & & & \\
\cline { 2 - 3 } "Los Angeles" & "U.S." & "9638" & "10714" & 8682 \\
"Manchester" & "U.K." & "4151" & "3827" & 11627 \\
"Mexico City" & "Mexico" & "16900" & "27872" & 32377 \\
"Sao Paolo" & "Brazil" & "14910" & "25354" & 33060 \\
"Singapore" & "Singapore" & "2556" & $" 2913 "$ & 32769 \\
"Sydney" & "Australia" & "3396" & "3708" & 10047 \\
"Tokyo-Yokahama" & "Japan" & "29971" & "29971" & 23356
\end{tabular}


Name:

Purpose:

Procedure:

Pass Condition: The responder verifies that file $\mathbf{R} 8 \mathbf{W} 7$ contains:

Node Name

"Los Angeles"

"Manchester"

"Mexico City"

"Singapore"

"Sydney"

"Tokyo-Yokahama"

"United"
Contents

"California"

"U.K."

$\begin{array}{rr}\text { "States" } & 100 \\ \text { "3827" } & 11627\end{array}$

"Mexico"

"Singapore"

"Australia"

"Japan"
"16900"

"3827"

"27872" 32377

"2556" "2913" 32769

"3396" "3708" 10047

"29971" "29971" 23356

Name:

NBS8-W-8

Purpose:

Replace "previous" FADU.

Procedure:

Replace the "current" FADU in file R8W8 with a new FADU identified as node "Rangoon" and whose data elements contain: "Burma", "2558", "3332", and 54426. This action should fail.

Pass Condition: The responder verifies that file R8W8 contains:

$\begin{array}{llrrr}\text { Node Name } & \text { Contents } & & & \\ \text { "Los Angeles" } & \text { "U.S." } & \text { "9638" } & \text { "10714" } & 8682 \\ \text { "Manchester" } & \text { "U.K." } & \text { "4151" } & \text { "3827" } & 11627 \\ \text { "Mexico City" } & \text { "Mexico" } & \text { "16900" } & \text { "27872" } & 32377 \\ \text { "Singapore" } & \text { "Singapore" } & \text { "2556" } & \text { "2913" } & 32769 \\ \text { "Sydney" } & \text { "Australia" } & \text { "3396" } & \text { "3708" } & 10047 \\ \text { "Tokyo-Yokahama" } & \text { "Japan" } & \text { "29971" } & \text { "29971" } & 23356\end{array}$


Name:

Purpose:

Procedure:

Pass Condition:
NBS8-W-9

Replace FADU whose node sequence matches an existing node.

Replace an FADU in file R8W9 identified as node "Singapore" and whose data elements contain: "Sir Thomas", "Stamford", "Raffles", and 1819.

The responder verifies that file $\mathbf{R} 8 \mathbf{W} 9$ contains:

$\begin{array}{llrrr}\text { Node Name } & \text { Contents } & & & \\ \text { "Los Angeles" } & \text { "U.S." } & \text { "9638" } & \text { "10714" } & 8682 \\ \text { "Manchester" } & \text { "U.K." } & \text { "4151" } & \text { "3827" } & 11627 \\ \text { "Mexico City" } & \text { "Mexico" } & \text { "16900" } & \text { "27872" } & 32377 \\ \text { "Singapore" } & \text { "Sir Thomas" } & \text { "Stamford" } & \text { "Raffles" } & 1819 \\ \text { "Sydney" } & \text { "Australia" } & \text { "3396" } & \text { "3708" } & 10047 \\ \text { "Tokyo-Yokahama" } & \text { "Japan" } & \text { "29971" } & \text { "29971" } & 23356\end{array}$

Name:

NBS8-W-10

Purpose:

Procedure:

Replace FADU whose node sequence does not match an existing node.

Replace an FADU in file R8W10 identified as node "Seoul" and whose data elements contain: "South Korea", "13665", "21976", and 39956.

Pass Condition: The responder verifies that file $\mathbf{R} 8 \mathbf{W 1 0}$ contains:

$\begin{array}{llrrr}\text { Node Name } & \text { Contents } & & & \\ \text { "Los Angeles" } & \text { "U.S." } & \text { "9638" } & \text { "10714" } & 8682 \\ \text { "Manchester" } & \text { "U.K." } & \text { "4151" } & \text { "3827" } & 11627 \\ \text { "Mexico City" } & \text { "Mexico" } & \text { "16900" } & \text { "27872" } & 32377 \\ \text { "Singapore" } & \text { "Singapore" } & \text { "2556" } & \text { "2913" } & 32769 \\ \text { "Seoul" } & \text { "South Korea" } & \text { "13665" } & \text { "21976" } & 39956 \\ \text { "Sydney" } & \text { "Australia" } & \text { "3396" } & \text { "3708" } & 10047 \\ \text { "Tokyo-Yokahama" } & \text { "Japan" } & \text { "29971" } & \text { "29971" } & 23356\end{array}$

Name:

NBS8-W-11

Purpose:

Insert a new FADU.

Procedure:

Insert a new FADU in file $\mathbf{R 8 W 1 1}$ identified as node "Adoration of the Magi" and whose data elements contain: "Mantegna", 10.4, FALSE, "8512121530-0600", null, 'A'H, and '1010'B.

Pass Condition: The responder verifies that the above data unit was inserted at the beginning of file $\mathbf{R 8 W 1 1 .}$ 


\section{Access Service Class Tests}

Name:

Purpose:

Procedure:

\section{NBS8-RR-1}

Perform multiple reads of an NBS-8 file.

The following actions operate on file $\mathbf{R 8 R}$. The received contents of these operations are stored into file A8RR1. The actions are:

1. Locate FADU whose node name is "Manchester".

2. Read "current" FADU.

3. Locate "next" FADU.

4. Read "next" FADU.

5. Locate "end" FADU.

6. Read "previous" FADU.

7. Locate "previous" FADU.

8. Read "current" FADU.

Pass Condition: The initiator verifies that the contents of file A8RR1 contains:

$\begin{array}{llrrr}\text { Node Name } & \text { Contents } & & & \\ \text { "Manchester" } & \text { "U.K." } & \text { "4151" } & \text { "3827" } & 11627 \\ \text { "Singapore" } & \text { "Singapore" } & \text { "2556" } & \text { "2913" } & 32769 \\ \text { "Tokyo-Yokahama" } & \text { "Japan" } & \text { "29971" } & \text { "29971" } & 23356 \\ \text { "Sydney" } & \text { "Australia" } & \text { "3396" } & \text { "3708" } & 10047\end{array}$


Name:

Purpose:

Procedure:

NBS8-RR-2

Perform multiple reads of an NBS-8 file.

The following actions operate on file $\mathbf{R 8 R}$. The received contents of these operations are stored into file A8RR2. The actions are:

1. Locate FADU whose node name is "Los Angeles".

2. Read "current" FADU.

3. Locate FADU whose node name is "Sydney".

4. Read "current" FADU.

5. Locate "previous" FADU.

6. Read "previous" FADU.

7. Locate "next" FADU.

8. Read "current" FADU.

9. Locate FADU whose node name is "Tokyo-Yokahama".

10. Read "current" FADU.

11. Locate "current" FADU.

Pass Condition: The initiator verifies that the contents of file A8RR2 contains:

Node Name

"Los Angeles"

"Sydney"

"Mexico City"

"Singapore"

"Tokyo-Yokahama"
Contents

"U.S."

"Australia"

"Mexico"

"Singapore"

"Japan"
"9638"

"3396"

"16900"

"2556"

"29971"

$\begin{array}{rr}\text { "10714" } & 8682 \\ \text { "3708" } & 10047 \\ \text { "27872" } & 32377 \\ \text { "2913" } & 32769 \\ \text { "29971" } & 23356\end{array}$


Name:

Purpose:

Procedure:

Pass Condition: The responder verifies that the contents of file R8WW1 contains:
NBS8-WW-1

Perform multiple writes to an NBS-8 file.

The following actions operate on file R8WW1. The actions are:

1. Insert an FADU whose FADU identifier is "Paris" and whose data elements contain: "France", "8633", "8800", 19983.

2. Locate FADU whose node name is Sydney.

3. Replace FADU "Sydney" with a new FADU whose identifier is "Sydney" and whose data elements contain: "Is A" "Lively", "City", 12345.

4. Replace the "next" FADU's data elements contents with "Is An", "Exciting", "City", 500.

5. Locate "begin" FADU.

6. Insert an FADU whose FADU identifier is "Kiev" and whose data elements contain: "USSR", "2489", "3237", 40145.

8. Locate FADU whose node name is "Tokyo-Yokahama".

9. Replace the "previous" FADU's data unit contents with: "Is Still A", "Lively" "City", 100.
Node Name

"Kiev"

"Los Angeles"

"Manchester"

"Mexico City"

"Paris"

"Singapore"

"Sydney"

"Tokyo-Yokahama"

\section{Contents}

"USSR"

"U.S."

"U.K."

"Mexico"

"France"

"Singapore"

"Is Still A"

"Is An"

$\begin{array}{rrr}\text { "2489" } & \text { "3237" } & 40145 \\ \text { "9638" } & \text { "10714" } & 8682 \\ \text { "4151" } & \text { "3827" } & 11627 \\ \text { "16900" } & \text { "27872" } & 32377 \\ \text { "8633" } & \text { "8800" } & 19983 \\ \text { "2556" } & \text { "2913" } & 32769 \\ \text { "Lively" } & \text { "City" } & 100 \\ \text { "Exciting" } & \text { "City" } & 500\end{array}$

Name:

NBS8-WW-2

Purpose:

Erase an NBS-8 file.

Procedure:

Locate "begin" of file R8WW2. Erase file R8WW2.

Pass Condition: The responder verifies that file R8WW2 only contains a root node with an empty data unit. 
Name:

Purpose:

Procedure:

\section{NBS8-RW-1}

Perform multiple reads and writes to an NBS-8 file.

The following actions operate on file R8RW1. The received contents of these operations are stored into file A8RW1. The actions are:

1. Locate FADU whose node name is "Mexico City".

2. Read "current" FADU.

3. Locate "begin" FADU.

4. Insert a new FADU whose node name is "Rome" and whose data elements contain: "Italy", "2944", "3129", and 42667.

5. Insert a new FADU whose node name is "Chicago" and whose data elements contain: "U.S.", "6500", "6568", and 8544.

6. Insert a new FADU whose node name is "Washington D.C." and whose data elements contain: "U.S.", "2456", "2700", and 6880 .

7. Locate FADU whose node name is "Washington D.C.".

8. Read "current" FADU.

9. Locate "previous" FADU.

10. Read "current" FADU.

11. Locate "begin" FADU.

12. Read "current" FADU.

Pass Condition: The initiator verifies that the contents of file A8RW1 contains:

\begin{tabular}{|c|c|c|c|c|}
\hline Node Name & Contents & & & \\
\hline "Mexico City" & "Mexico" & "16900" & "27872" & 32377 \\
\hline "Washington D.C." & "U.S." & "2456" & "2700" & 6880 \\
\hline "Tokyo-Yokahama" & "Japan" & "29971" & "29971" & 23356 \\
\hline "Chicago" & "U.S." & "6500" & "6568" & 8544 \\
\hline "Los Angeles" & "U.S." & "9638" & "10714" & 8682 \\
\hline "Manchester" & "U.K." & "4151" & "3827" & 11627 \\
\hline "Mexico City" & "Mexico" & "16900" & "27872" & 32377 \\
\hline "Rome" & "Italy" & "2944" & "3129" & 42667 \\
\hline "Singapore" & "Singapore" & "2556" & "2913" & 32769 \\
\hline "Sydney" & "Australia" & "3396" & "3708" & 10047 \\
\hline "Tokyo-Yokahama" & "Japan" & "29971" & "29971" & 23356 \\
\hline "Washington D.C." & "U.S." & "2456" & "2700" & 6880 \\
\hline
\end{tabular}


Name:

Purpose:

Procedure:
NBS8-RW-2

Erase FADUs in an NBS-8 file.

The following actions operate on file R8RW2. The received contents of these operations are stored into file A8RW2. The actions are:

1. Locate FADU whose node name is "Singapore".

2. Erase "previous" FADU.

3. Erase "current" FADU.

4. Erase "next" FADU.

5. Erase FADU whose node name is "Manchester".

6. Erase FADU whose node name is "Los Angeles".

7. Read "begin" FADU.

Pass Condition: The initiator verifies that the contents of file A8RW2 contains:

Node Name

"Sydney"

\section{Contents}

"Australia" "3396" "3708" 10047

Name:

Purpose:

Procedure:

NBS8-RW-3

Read first FADU, then erase the "previous" FADU in an NBS-8 file. The following actions operate on file R8RW3. The actions are:

1. Read FADU whose node name is "Los Angeles".

2. Erase "previous" FADU. This action should fail.

Pass Condition: The responder verifies that file R8RW3 contains:

$\begin{array}{llrrr}\text { Node Name } & \text { Contents } & & & \\ \text { "Los Angeles" } & \text { "U.S." } & \text { "9638" } & \text { "10714" } & 8682 \\ \text { "Manchester" } & \text { "U.K." } & \text { "4151" } & \text { "3827" } & 11627 \\ \text { "Mexico City" } & \text { "Mexico" } & \text { "16900" } & \text { "27872" } & 32377 \\ \text { "Singapore" } & \text { "Singapore" } & \text { "2556" } & \text { "2913" } & 32769 \\ \text { "Sydney" } & \text { "Australia" } & \text { "3396" } & \text { "3708" } & 10047 \\ \text { "Tokyo-Yokahama" } & \text { "Japan" } & \text { "29971" } & \text { "29971" } & 23356\end{array}$




\subsection{NBS-9 Test Cases}

Name: $\quad$ NBS9-R-1

Purpose: $\quad$ Read the virtual NBS-9 file.

Procedure: $\quad$ Read the virtual NBS-9 file called DIRLIS.

Pass Condition: The initiator verifies with the responder that the file directory entries returned by reading the virtual file DIRLIS contains the current file directory entries found on the responder's filestore. DIRLIS does not need to be a physical file stored on the responder's filestore. 


\subsection{Limited File Management Test Cases}

Name:

Purpose:

Procedure:

Pass Condition:

Name:

Purpose:

Procedure:

Pass Condition:

Name:

Purpose:

Procedure:

Pass Condition: The responder verifies that file RLFM3 was deleted and recreated with the file's previously existing attributes.

Name:

\section{LFM-4}

Purpose:

Procedure:

\section{Pass Condition:}

Create a file when the file does not exist.

Create file RLFM1 with contents type FTAM-3 and permitted actions of read, read attributes, extend, delete file, and replace. The override parameter has no effect since the file will not exist on the responder's filestore. A new file is created with the new, specified attributes. attributes.

\section{LFM-2}

Create a file with override set to "delete and create with new attributes". Create file RLFM2 with contents type FTAM-3 and permitted actions of read, read attributes, and delete file. The override parameter is set such that the file is deleted if it already exists and a new file is created with the new, specified attributes. attributes, and the deletion of the previous file by the same name.

\section{LFM-3}

Create a file with override set to "delete and create with old attributes". Create file RLFM3 with contents type FTAM-3 and permitted actions of read, read attributes, and delete file. The override parameter is set such that the file is deleted if it already exists and a new file is created with the old, previous attributes.

Create a file with override set to "select old file".

Create file RLFM4 on the responder's virtual filestore. The override parameter is set such that the file is selected if it already exists. The file RLFM4 exists in the responder's filestore and therefore will be selected. The initiator replaces the contents of file RLFM4 with the contents of file ILFM4.

The responder verifies that the contents of file RLFM4 is identical to the contents defined for file ILFM4. The supported file attributes should be checked. 
Name:

Purpose:

Procedure

Pass Condition:

Name:

Purpose:

Procedure:

Pass Condition:

\section{LFM-5}

Create a file with override set to "create failure".

Create file RLFM5 on the responder's virtual filestore. The override parameter is set such that the create fails if the file already exists.

The initiator verifies that the responder rejected the creation request with a suitable diagnostic. The responder verifies that file RLFM5 has not changed.

LFM-6

Read all supported file attributes.

Read all file attributes supported for file RLFM6.

The initiator verifies that at a minimum the following attributes are returned:

1. Filename

2. Permitted Actions

3. Contents Type

The initiator verifies with the responder that all values returned match the actual values defined for file RLFM6.

Name:

LFM-7

Purpose:

Permitted actions prevent reading file attributes.

Procedure:

Read all file attributes for file RLFM7.

Pass Condition: The initiator verifies that an error indicating that the file attributes can not be read is returned.

Name: $\quad$ LFM-8

Purpose: $\quad$ Delete a file.

Procedure: $\quad$ Delete file RLFM8.

Pass Condition: The responder verifies that file RLFM8 was deleted.

Name:

LFM-9

Purpose:

Delete a non-existent file.

Procedure:

Delete file RXYZ. File RXYZ must not exist on the responder's filestore.

Pass Condition: The initiator verifies that an error indicating that the file does not exist is returned. 
Name: $\quad$ LFM-10

Purpose: $\quad$ Permitted actions prevent deleting a file.

Procedure: $\quad$ Delete file RLFM10.

Pass Condition: The initiator verifies that an error indicating that the file can not be deleted is returned.

Name:

Purpose:

Procedure:

Pass Condition:

\section{LFM-11}

Read the storage group file attributes.

Read at least the storage group attributes of file RLFM11.

The initiator verifies that at a minimum the following attributes in the storage group are returned:

1. File Availability

2. Filesize

The initiator verifies that all values returned match the actual values defined for file RLFM11. The value for the filesize attribute is based on the real filestore's representation and will not necessarily be 2048 octets. 
Name:

Purpose:

Procedure:

Pass Condition:

\section{LFM-12}

Check storage file attribute values after reading a file.

Read at least the following file attributes for file RLFM12:

1. Date and time of last modification

2. Date and time of last read access

3. Date and time of last attribute modification

4. Identity of creator

5. Identity of last modifier

6. Identity of last reader

7. Identity of last attribute modifier

Read file RLMF12. Read file attributes listed above again.

The initiator verifies that the following file attributes have been updated:

1. Date and time of last read access

2. Identity of last reader

The initiator also verifies that the following file attributes did not change:

1. Date and time of last modification

2. Date and time of last attribute modification

3. Identity of creator

4. Identity of last modifier

5. Identity of last attribute modifier 
Name:

Procedure:

Pass Condition:
Purpose:

\section{LFM-13}

Check storage attribute values after extending a file.

Read at least the following file attributes for file RLFM13:

1. Date and time of last modification

2. Date and time of last read access

3. Date and time of last attribute modification

4. Identity of creator

5. Identity of last modifier

6. Identity of last reader.

7. Identity of last attribute modifier

Extend file RLMF13 with the contents of file ILFM13. Read the file attributes listed above again.

The initiator verifies that the following file attributes have been updated:

1. Date and time of last modification

2. Identity of last modifier

The initiator also verifies that the following file attributes did not change:

1. Date and time of last read access

2. Date and time of last attribute modification

3. Identity of creator

4. Identity of last reader

5. Identity of last attribute modifier

Name:

LFM-14

Purpose:

Read the security group file attributes.

Procedure: Read at least the security group attributes of file RLFM14.

Pass Condition: The initiator verifies that at a minimum the following attributes in the security group are returned:

\section{Access Control}

The initiator verifies that all values returned match the actual values defined for file RLFM14. 


\subsection{Enhanced File Management Test Cases}

Name:

Purpose:

Procedure:

Name:

Purpose:

Procedure:

Pass Condition:

\section{EFM-1}

Change kernel group file attributes.

The following kernel group file attributes can be changed:

\section{Filename}

For file REFM1, change its filename attribute from REFM1 to RNAMECHG.

Pass Condition: The responder verifies that the filename attribute was changed to RNAMECHG.

\section{EFM-2}

Change filename to a filename that already exists.

For file REFM2, change its filename attribute from REFM2 to REFM2A. The initiator verifies that an error is returned. Possible errors are "File Already Exists" or "Bad Attribute Value".

Name:

Purpose:

Procedure:

Pass Condition:

\section{EFM-3}

Attempt to change filename attribute for a non-existent file.

For file RXYZ, change its filename attribute from RXYZ to RXYZABC. File RXYZ must not exist on the responder's filestore.

The initiator verifies that an error indicating that the file does not exist is returned.

Name:

\section{EFM-4}

Purpose:

Permitted actions prevent changing file attributes.

Procedure: For file REFM4, change its filename attribute from REFM4 to REFM4A.

Pass Condition: The initiator verifies that an error indicating that the file attributes can not be changed is returned. 
Name:

Purpose:

Procedure:

\section{EFM-5}

Change storage group file attributes.

The following storage group file attributes can be changed:

1. Storage Account

2. File Availability

3. Future Filesize

For file REFM5, change each of the supported storage group file attributes. At a minimum, read the file availability attribute and change its value from "immediate availability" to "deferred availability". (The file availability attribute for file REFM5 is initially set to "immediate availability".) Read the file availability attribute again. (Note: The initiator and responder must coordinate attribute values for the storage account file attribute since its representation may be system dependent.)

Pass Condition: The initiator verifies that the changed storage group attributes for file REFM5 match those specified by the initiator. At a minimum, the initiator verifies that the file availability attribute was initially "immediately available" and then was changed to "deferred availability". The responder also verifies that the storage group attributes for file REFM5 were changed to those values specified by the initiator. At a minimum, the responder verifies that the file availability attribute was changed to "deferred availability". 
Name:

Purpose:

Procedure:
EFM-6

Check storage file attribute values after changing filename attribute.

Read at least the following file attributes for file REFM6:

1. Date and time of last modification

2. Date and time of last read access

3. Date and time of last attribute modification

4. Identity of creator

5. Identity of last modifier

6. Identity of last reader

7. Identity of last attribute modifier

Change the filename attribute for file REMF6 from REFM6 to REFM6A. Read file attributes listed above again.

Pass Condition: The initiator verifies that the following file attributes have been updated:

1. Date and time of last attribute modification

2. Identity of last attribute modifier

The initiator also verifies that the following file attributes did not change:

1. Date and time of last modification

2. Date and time of last read access

3. Identity of creator

4. Identity of last modifier

5. Identity of last reader 
Name:

Purpose:

Procedure:

\section{EFM-7}

Change security group file attributes.

The following security group file attributes can be changed:

1. Access Control

2. Legal Qualifications

For file REFM7, change each of the supported security group file attributes. At a minimum, the access control attribute must be changed. (Note: The initiator and responder must coordinate attribute values for the security file attributes since their representation may be system dependent.)

Pass Condition: The initiator verifies that the changed security group attributes for file REFM7 match those specified by the initiator. The responder also verifies that the security group attributes for file REFM7 were changed to those values specified by the initiator. 


\section{Test Files And Their Contents}

Section 3 defines the test files used by the FTAM Interoperability Tests. For each test file, the kernel file attributes are assumed to exist and, except where noted, the permitted actions supported for a file are:

a) Actions Supported

Read

Insert

(for FTAM-2, NBS-6, NBS-7, and NBS-8 files)

Replace

Extend

Erase

(for access service class tests)

Read Attributes

(for limited file management tests)

Change Attributes

(for enhanced file management tests)

Delete File

(for limited file management tests)

b) FADU-identity Groups Supported

Traversal

(for NBS-7 files)

Reverse Traversal (for NBS-7 files)

Random Order

(for NBS-8 files)

The contents type attribute is specified by the file's document type.

Each test file is defined by its filename, document type, and file contents. In defining the FTAM-1, FTAM-2, and FTAM-3 test files, the document type field states the document type name, followed by values for the document type parameters in the sequence described by the document type definitions. For example, the document type field for test file R1R1 is:

Document Type: FTAM-1, 22, 134, 'not significant'

This states that file R1R1 is an FTAM-1 file, and has a universal class number of 22, a maximum string length of 134 characters, and a string significance of 'not significant'. This order follows the parameter sequence for the FTAM-1 document type defined in ISO 8571-2 as:

PARAMETERS ::= SEQUENCE \{ universal-class-number [0] IMPLICIT INTEGER OPTIONAL, maximum-string-length [1] IMPLICIT INTEGER OPTIONAL, string-significance [2] IMPLICIT INTEGER \{variable(0), fixed(1), not-significant(2)\} OPTIONAL \} 


\subsection{FILES USED BY FTAM-1 TEST CASES}

\section{TEST NAME: $\quad$ FTAM1-R-1}

Filename: $\quad$ R1R1

Document Type: FTAM-1, 22, 134, 'not-significant'

File Contents: This file contains 50 strings. Each string consists of the name "FTAM1A" followed by the 128 printable characters (in ascending order) taken from the ISO $646 \mathrm{G} 0$ character set starting with position $2 / 0$ and ending with position $7 / 14$ ( 95 characters) then beginning again with $2 / 0$ and ending with $4 / 0$ ( 33 characters). This results in a file that contains 6700 characters.

Filename: $\quad$ A1R1

Document Type: FTAM-1, 22, 134, 'not-significant'

File Contents: Generated by running test.

\section{TEST NAME: $\quad$ FTAM1-R-2}

Filename: $\quad$ R1R2

Document Type: FTAM-1, 27, 134, 'not-significant'

File Contents: This file contains 50 strings. The first 25 strings consists of the name "FTAM1C" followed by the 128 printable characters (in ascending order) taken from the ISO 8859-1 G0 and G1 character sets starting with position $2 / 0$ and ending with position $7 / 14$ ( 95 characters from $\mathrm{G} 0$ ) followed by the characters $10 / 0$ through $12 / 0$ (33 characters from G1). The second 25 strings consists of the name "FTAM1C" followed by the 128 printable characters (in ascending order) taken from the ISO 8859-1 G0 and G1 character sets starting with position $11 / 15$ and ending with position $15 / 15$ ( 65 characters from $\mathrm{G} 1$ ) followed by the characters $2 / 0$ through 5/14 (63 characters from G0). This results in a file that contains 6700 characters.
Filename:
A1R2
Document Type: FTAM-1, 27, 134, 'not-significant'
File Contents: Generated by running test. 


\section{TEST NAME: $\quad$ FTAM1-R-3}

Filename: $\quad$ A1R3

Document Type: FTAM-1, 27, 134, 'not-significant'

File Contents: Generated by running test.

\section{TEST NAME: $\quad$ FTAM1-W-1}

Filename: $\quad$ R1W1

Document Type: FTAM-1, 22, 134, 'not-significant'

File Contents: $\quad$ Same as file R1R1.

File Name: $\quad$ I1W 1

Document Type: FTAM-1, 22, 134, 'not-significant'

File Contents: This file contains 50 strings. Each string consists of the name "FTAM1B" followed by the 128 printable characters (in descending order) taken from the ISO $646 \mathrm{GO}$ character set starting with position $7 / 14$ and ending with position $2 / 0$ (95 characters) then beginning again with $7 / 14$ and ending with $5 / 14$ (33 characters). This results in a file that contains 6700 characters.

\section{TEST NAME: $\quad$ FTAM1-W-2}

Filename: $\quad$ R1W2

Document Type: FTAM-1, 27, 134, 'not-significant'

File Contents: Same as file R1R2.

Filename: $\quad$ I1W2

Document Type FTAM-1, 27, 134, 'not-significant'

File Contents: This file contains 50 strings. The first 25 strings consists of the name "FTAM1D" followed by the 128 printable characters (in descending order) taken from the ISO $8859-1 \mathrm{G0}$ and G1 character sets starting with position 15/15 and ending with position 10/0 (96 characters from G1) followed by the characters $7 / 14$ through $5 / 15$ (32 characters from $\mathrm{G} 0$ ). The second 25 strings consists of the name "FTAM1D" followed by the 128 printable characters (in descending order) taken from the ISO 8859-1 G0 and G1 character sets starting with position $6 / 0$ and ending with position $2 / 0$ ( 65 characters from $\mathrm{G} 0$ ) followed by the characters $15 / 15$ through 12/1 (63 characters from G1). This results in a file that contains 6700 characters. 
TEST NAME: $\quad$ FTAM1-W-3

Filename: $\quad$ R1W3

Document Type: FTAM-1, 22, 134, 'not-significant'

File Contents: Same as file R1R1.

Filename: IIW3

Document Type: FTAM-1, 22, 134, 'not-significant'

File Contents: Same as file I1W1.

TEST NAME: $\quad$ FTAM1-W-4

Filename: $\quad$ R1W4

Document Type: FTAM-1, 27, 134, 'not-significant'

File Contents: Same as file R1R2.

Filename: $\quad$ I1W4

Document Type: FTAM-1, 27, 134, 'not-significant'

File Contents: Same as file I1W2.

TEST NAME: $\quad$ FTAM1-WW-1

Filename: $\quad$ R1WW1

Document Type: FTAM-1, 22, 134, 'not-significant'

File Contents: Same as file R1R1. 


\subsection{FILES USED BY FTAM-2 TEST CASES}

TEST NAMES: All tests prefixed by FTAM2-R.

Filename: $\quad$ R2R

Document Type: FTAM-2, 25, 132, 'not-significant'

File Contents: This file contains 12 FADUs, each containing one string. The strings for the data units are:

10 'O' characters,

20 'S' characters,

30 'I' characters,

40 ' $F$ ' characters,

50 ' $\mathrm{T}$ ' characters,

60 ' $\mathrm{A}$ ' characters,

70 ' $\mathrm{M}$ ' characters,

60 ' $\mathrm{T}$ " characters,

50 'E' characters,

40 ' $S$ ' characters,

30 ' $\mathrm{T}$ ' characters, and

20 'S' characters.

TEST NAME: $\quad$ FTAM2-R-1

Filename: $\quad$ A2R1

Document Type: FTAM-2, 25, 132, 'not-significant'

File Contents: Generated by running test.

TEST NAME: $\quad$ FTAM2-W-1

Filename: $\quad$ R2W1

Document Type: FTAM-2, 25, 132, 'not-significant'

File Contents: $\quad$ Same as file R2R.

TEST NAME: $\quad$ FTAM2-RR-1

Filename: $\quad$ A2RR1

Document Type: FTAM-2, 25, 132, 'not-significant'

File Contents: Generated by running test. 
TEST NAME: $\quad$ FTAM2-WW-1

Filename: $\quad$ R2WW1

Document Type: FTAM-2, 25, 132, 'not-significant'

File Contents: Same as file R2R.

TEST NAME: $\quad$ FTAM2-WW-2

Filename: $\quad$ R2WW2

Document Type: FTAM-2, 25, 132, 'not-significant'

File Contents: Same as file R2R.

TEST NAME: $\quad$ FTAM2-RW-1

Filename: $\quad$ R2RW1

Document Type: FTAM-2, 25, 132, 'not-significant'

File Contents: Same as file R2R.

Filename: $\quad$ A2RW1

Document Type: FTAM-2, 25, 132, 'not-significant'

File Contents: Generated by running test. 


\subsection{FILES USED BY FTAM-3 TEST CASES}

\section{TEST NAME: $\quad$ FTAM3-R-1}

Filename: $\quad$ R3R1

Document Type: FTAM-3, 512, 'not-significant'

File Contents: This file contains 4 strings. Each string consists of the name "FTAM3A" followed by the 2568 -bit combinations in descending order from 255 to 0 followed by the 250 8-bit combinations in descending order from 249 to 0 . This results in a file of 2048 characters.

Filename: $\quad$ A3R1

Document Type: FTAM-3, 512, 'not-significant'

File Contents: Generated by running test.

\section{TEST NAME: $\quad$ FTAM3-R-2}

Filename: $\quad$ R3R2

Document Type: FTAM-3, 512, 'not-significant'

File Contents: This file contains 1540 strings. Each string consists of the name "FTAM3B" followed by the 2568 -bit combinations in ascending order from 0 to 255 followed by the 2508 -bit combinations in ascending order from 0 to 249 . This results in a file of 788,480 characters.

Filename: $\quad \mathrm{A} 3 \mathrm{R} 2$

Document Type: FTAM-3, 512, 'not-significant'

File Contents: Generated by running test.

\section{TEST NAME: $\quad$ FTAM3-R-3}

Filename: $\quad$ R1234567

Document Type: FTAM-3, 512, 'not-significant'

File Contents: $\quad$ Same as file R3R1.

Filename: $\quad$ A1234567

Document Type: FTAM-3, 512, 'not-significant'

File Contents: Generated by running test. 
TEST NAME: $\quad$ FTAM3-R-4

Filename: $\quad$ RXYZ

Document Type: FTAM-3, 512, 'not-significant'

File Contents: File RXYZ must not exist on the responder's filestore.

Filename: $\quad$ AXYZ

Document Type: FTAM-3, 512, 'not-significant'

File Contents: The file AXYZ, if created, should be empty.

TEST NAME: $\quad$ FTAM3-R-7

Filename: $\quad$ R3R7

Document Type: FTAM-3, 512, 'not-significant'

File Contents: $\quad$ Same as file R3R1. The permitted actions for file R3R7 are replace and extend. The read permitted action is not supported for file R3R7.

Filename: $\quad$ A3R7

Document Type: FTAM-3, 512, 'not-significant'

File Contents: The file A3R7, if created, should be empty.

TEST NAME: $\quad$ FTAM3-W-1

Filename: $\quad$ R3W1

Document Type: FTAM-3, 512, 'not-significant'

File Contents: Same as file R3R1.

Filename: $\quad$ I3W1

Document Type: FTAM-3, 512, 'not-significant'

File Contents: This file contains 4 strings. Each string consists of the filename "FTAM3C" followed by the 2568 -bit combinations in ascending order from 0 to 255 followed by the 250 8-bit combinations in ascending order from 0 to 249. This results in a file of 2048 characters. 
TEST NAME: $\quad$ FTAM3-W-2

Filename: $\quad$ R3W2

Document Type: FTAM-3, 512, 'not-significant'

File Contents: Same as file R3R1.

Filename: $\quad$ I3W2

Document Type: FTAM-3, 512, 'not-significant'

File Contents: Same as file R3R2.

\section{TEST NAME: $\quad$ FTAM3-W-3}

Filename: R3W3

Document Type: FTAM-3, 512, 'not-significant'

File Contents: Same as file R3R2.

Filename: $\quad$ I3W3

Document Type: FTAM-3, 512, 'not-significant'

File Contents: Same as file R3R1.

\section{TEST NAME: $\quad$ FTAM3-W-4}

Filename: R3W4

Document Type: FTAM-3, 512, 'not-significant'

File Contents: $\quad$ Same as file R3R1.

Filename: $\quad$ I3W4

Document Type: FTAM-3, 512, 'not-significant'

File Contents: Same as file I3W1.

TEST NAME: $\quad$ FTAM3-W-5

Filename: $\quad$ R3W5

Document Type: FTAM-3, 512, 'not-significant'

File Contents: $\quad$ Same as file R3R1. Permitted actions for file R3W5 are read and extend. The replace permitted action is not supported for file R3W5.

Filename: $\quad$ I3W5

Document Type: FTAM-3, 512, 'not-significant'

File Contents: Same as file I3W1. 


\section{TEST NAME: $\quad$ FTAM3-WW-1}

Filename: $\quad$ R3WW1

Document Type: FTAM-3, 512, 'not-significant'

File Contents: Same as file R3R1. 


\subsection{FILES USED BY NBS-6 TEST CASES}

TEST NAMES: All tests prefixed by NBS6-R

Filename:

R6R

Document Type: NBS-6

File Contents: The data elements of this file are represented by:

$\begin{array}{ll}\begin{array}{ll}\text { City-Elevation-and-Precipitation ::= SEQUENCE \{ } \\ \text { city }\end{array} & \{\text { general, 15 \}, } \\ \text { country } & \{\text { ia5, 15 \}, } \\ \text { elevation } & \{\text { int, } 2\}, \\ \text { elevation-in-binary } & \{\text { bit, } 2\}, \\ \text { elevation-in-octets } & \{\text { octet, } 2\}, \\ \text { annual-precipitation } & \{\text { float, 16, 8 \}, } \\ \text { unit-of-measurement } & \{\text { graphic, 10\}, } \\ \text { precipitation-over-50 } & \text { boolean } \\ \text { \} } & \end{array}$

The data element values for the data units are:

$\begin{array}{llrrrrrl}\text { "Berlin" } & \text { "Germany" } & 187 & \text { '10111011'B } & \text { '66'H } & 23.1 & \text { "inches" } & \text { FALSE } \\ \text { "London" } & \text { "England" } & 149 & ' 10010101 \text { 'B } & \text { '95'H } & 22.9 & \text { "inches" } & \text { FALSE } \\ \text { "Manila" } & \text { "Philippines" } & 49 & ' 110001 \text { 'B } & \text { '31'H } & 82.0 & \text { "inches" } & \text { TRUE } \\ \text { "Paris" } & \text { "France" } & 164 & ' 10100100 \text { 'B } & \text { 'A4'H } & 22.3 & \text { "inches" } & \text { FALSE } \\ \text { "Sydney" } & \text { "Australia" } & 62 & ' 111110^{\prime} \mathrm{B} & \text { '3E'H } & 46.5 & \text { "inches" } & \text { FALSE } \\ \text { "Tokyo" } & \text { "Japan" } & 19 & \text { '10011'B } & \text { '13'H } & 61.6 & \text { "inches" } & \text { TRUE }\end{array}$

TEST NAME: $\quad$ NBS6-R-1

Filename: $\quad A 6 R 1$

Document Type: NBS-6

File Contents: Generated by running test. 
TEST NAME: $\quad$ NBS6-R-2

Filename: $\quad$ R6R2

Document Type: NBS-6

File Contents: The data elements of this file are represented by:

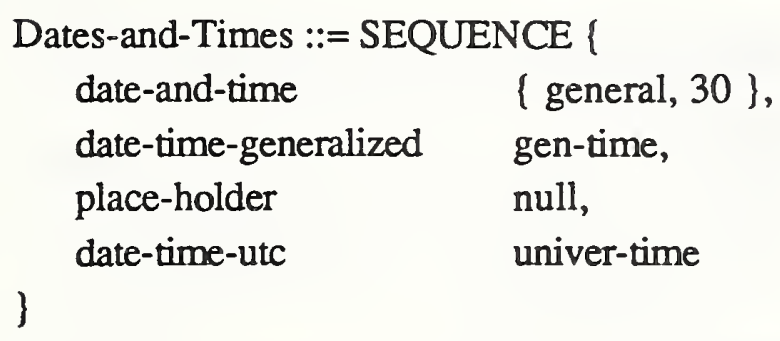

The data element values for the data units are:

$\begin{array}{llll}\text { "February 29, } 1992 \text { 8:45 a.m." } & \text { "19920229084500.0" } & \text { null } & \text { "9202290845Z" } \\ \text { "December 25, } 1980 \text { 11:30 p.m." } & \text { "19801225113000.0" } & \text { null } & \text { "8012251130Z" } \\ \text { "January 15, } 1995 \text { 2:15 p.m." } & \text { "19950115141500.0-0600" } & \text { null } & \text { "9501151415-0600" }\end{array}$

Filename: $\quad$ A6R2

Document Type: NBS-6

File Contents: Generated by running test.

TEST NAME: $\quad$ NBS6-W-1

Filename: $\quad$ R6W1

Document Type: NBS-6

File Contents: Same as file R6R.

TEST NAME: $\quad$ NBS6-W-2

Filename: $\quad$ R6W2

Document Type: NBS-6

File Contents: Same as file R6R2.

TEST NAME: $\quad$ NBS6-RR-1

Filename: $\quad$ A6RR1

Document Type: NBS-6

File Contents: Generated by running test. 
NBS-6 Test Files

TEST NAME: $\quad$ NBS6-WW-1

Filename: $\quad$ RWW1

Document Type: NBS-6

File Contents: Same as file R6R.

TEST NAME: $\quad$ NBS6-WW-2

Filename: $\quad$ R6WW2

Document Type: NBS-6

File Contents: Same as file R6R.

TEST NAME: $\quad$ NBS6-RW-1

Filename: $\quad$ R6RW1

Document Type: NBS-6

File Contents: Same as file R6R.

Filename: $\quad$ A6RW1

Document Type: NBS-6

File Contents: Generated by running test. 


\subsection{FILES USED BY NBS-7 TEST CASES}

TEST NAMES: All tests prefixed by NBS7-R

Filename: $\quad$ R7R

Document Type: NBS-7

File Contents: The data elements of this file are represented by:

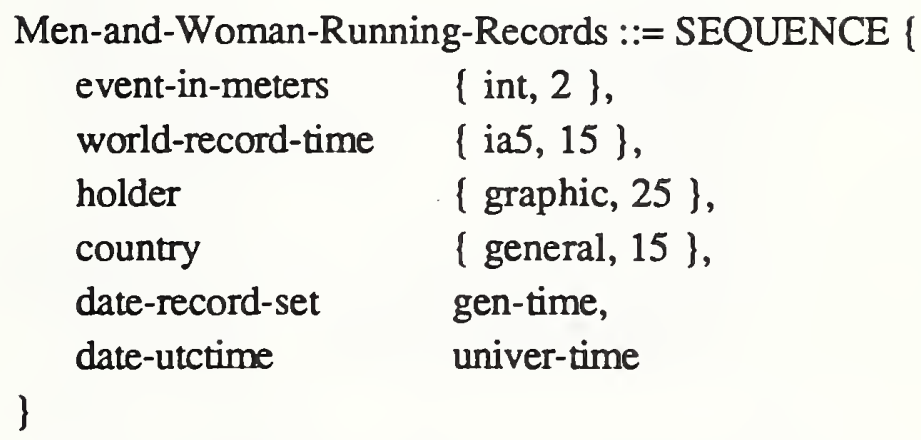

The data element values for the data units are:

$\begin{array}{llllll}100 & \text { "9.83s" } & \text { "Ben Johnson" } & \text { "Canada" } & \text { "19870830151500.0" } & \text { "8708301515Z" } \\ 200 & \text { "19.72s" } & \text { "Pietro Mennea" } & \text { "Italy" } & \text { "19790917161600.0" } & \text { "7909171616Z" } \\ 400 & \text { "47.60s" } & \text { "Marita Koch" } & \text { "East Germany" "19851006171700.0" } & \text { "8510061717Z" } \\ 1000 & \text { "2m, 12.18s" } & \text { "Sebastian Coe" } & \text { "Great Britain" } & \text { "19810711181800.0" } & \text { "8107111818Z" } \\ 3000 & \text { "7m, 32.1s" } & \text { "Henry Rono" } & \text { "Kenya" } & \text { "19780727191900.0" } & \text { "7807271919Z" }\end{array}$

TEST NAME: $\quad$ NBS7-R-1

Filename: $\quad$ A7R1

Document Type: NBS-7

File Contents: Generated by running test.

\section{TEST NAME: $\quad$ NBS7-R-4}

Filename: $\quad$ A7R4

Document Type: NBS-7

File Contents: Generated by running test. 


\section{TEST NAME: $\quad$ NBS7-R-9}

Filename: $\quad$ R7R9

Document Type: NBS-7

File Contents: The data elements of this file are represented by:

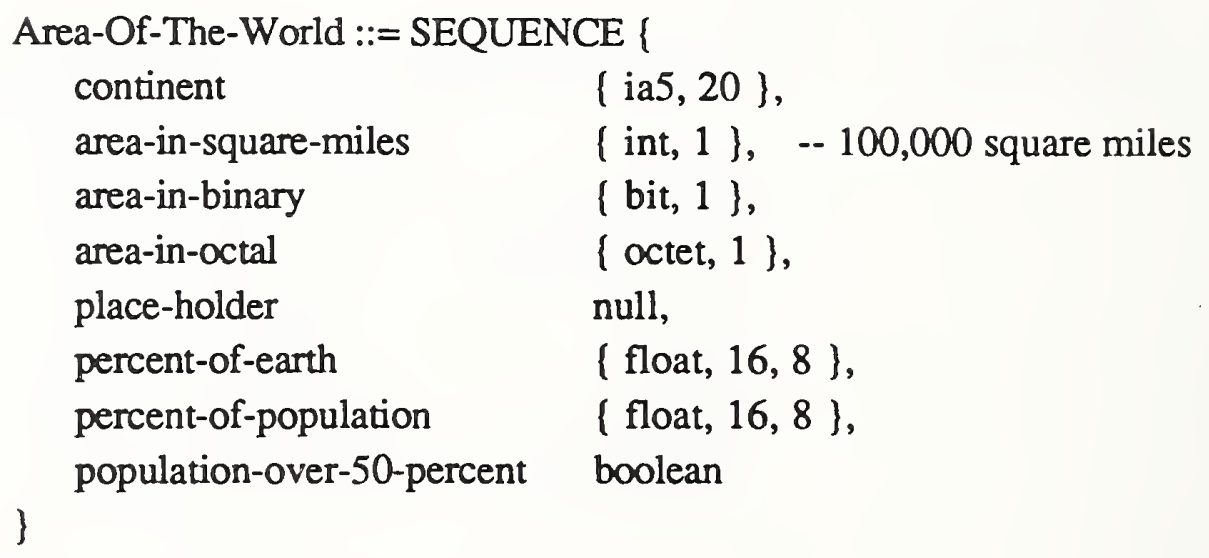

The data element values for the data units are:

$\begin{array}{lrrrrrrl}\text { "Europe" } & 38 & ' 100110 ' \mathrm{~B} & ' 26 ' \mathrm{H} & \text { null } & 6.6 & 13.5 & \text { FALSE } \\ \text { "Asia" } & 173 & ' 10101101 \text { 'B } & \text { 'AD'H } & \text { null } & 29.9 & 60.0 & \text { TRUE } \\ \text { "Africa" } & 117 & ' 1110101 \text { 'B } & ' 75 ' \mathrm{H} & \text { null } & 20.2 & 12.2 & \text { FALSE }\end{array}$

Filename: $\quad$ A7R9

Document Type: NBS-7

File Contents: Generated by running test.

TEST NAME: $\quad$ NBS7-W-1

Filename: $\quad$ RTW1

Document Type: NBS-7

File Contents: Same as file R7R.

TEST NAME: $\quad$ NBS7-W-2

Filename: $\quad$ R7W2

Document Type: NBS-7

File Contents: Same as file R7R. 
TEST NAME: $\quad$ NBS7-W-3

Filename: $\quad$ R7W3

Document Type: NBS-7

File Contents: Same as file R7R.

TEST NAMES: NBS7-W-4 through NBS7-W-5

Filename: $\quad$ R7W5

Document Type: NBS-7

File Contents: Same as file R7R.

TEST NAME: $\quad$ NBS7-W-6

Filename: $\quad$ R7W6

Document Type: NBS-7

File Contents: Same as file R7R.

TEST NAMES: $\quad$ NBS7-W-7 through NBS7-W-10

Filename: $\quad$ R7W10

Document Type: NBS-7

File Contents: Same as file R7R.

TEST NAME: $\quad$ NBS7-W-11

Filename: $\quad$ R7W11

Document Type: NBS-7

File Contents: Same as file R7R.

TEST NAME: $\quad$ NBS7-W-12

Filename: $\quad$ RTW12

Document Type: NBS-7

File Contents: $\quad$ Same as file R7R9. 
TEST NAME: $\quad$ NBS7-RR-1

Filename: $\quad$ R7RR1

Document Type: NBS-7

File Contents: The data elements of this file are represented by:

$$
\begin{array}{lc}
\begin{array}{ll}
\text { Languages-of-the-World ::= } & \text { SEQUENCE }\{ \\
\begin{array}{l}
\text { language } \\
\text { place-holder }
\end{array} & \{\text { ia5, 15 }\}, \\
\text { spoken-by-in-millions } & \text { null, } \\
\text { \} int, 2 }\}
\end{array}
\end{array}
$$

The data element values for the data units are:

$\begin{array}{llr}\text { "Arabic" } & \text { null } & 187 \\ \text { "English" } & \text { null } & 431 \\ \text { "Esperanto" } & \text { null } & 2 \\ \text { "French" } & \text { null } & 117 \\ \text { "German" } & \text { null } & 118 \\ \text { "Italian" } & \text { null } & 63 \\ \text { "Japanese" } & \text { null } & 124 \\ \text { "Korean" } & \text { null } & 68 \\ \text { "Mandarin" } & \text { null } & 825 \\ \text { "Portuguese" } & \text { null } & 169 \\ \text { "Russian" } & \text { null } & 289 \\ \text { "Spanish" } & \text { null } & 320\end{array}$

Filename: $\quad$ A7RR1

Document Type: NBS-7

File Contents: Generated by running test.

TEST NAME: $\quad$ NBS7-RR-2

Filename: $\quad$ A7RR2

Document Type: NBS-7

File Contents: Generated by running test.

TEST NAME: $\quad$ NBS7-WW-1

Filename: $\quad$ RTWW1

Document Type: NBS-7

File Contents: Same as file R7RR1. 
TEST NAME: $\quad$ NBS7-WW-2

Filename: $\quad$ R7WW2

Document Type: NBS-7

File Contents: Same as file R7RR1.

TEST NAME: $\quad$ NBS7-WW-3

Filename: $\quad$ R7WW3

Document Type: NBS-7

File Contents: $\quad$ Same as file R7RR1.

TEST NAME: $\quad$ NBS7-RW-1

Filename: $\quad$ R7RW1

Document Type: NBS-7

File Contents: Same as file R7RR1.

Filename: $\quad$ A7RW1

Document Type: NBS-7

File Contents: Generated by running test.

TEST NAME: $\quad$ NBS7-RW-2

Filename: $\quad$ R7RW2

Document Type: NBS-7

File Contents: $\quad$ Same as file R7RR1.

Filename: $\quad$ A7RW2

Document Type: NBS-7

File Contents: Generated by running test.

TEST NAME: NBS7-RW-3

Filename: $\quad$ R7RW3

Document Type: NBS-7

File Contents: $\quad$ Same as file R7RW2 after running test case NBS7-RW-2.

Filename: $\quad$ A7RW3

Document Type: NBS-7

File Contents: Generated by running test. 


\subsection{FILES USED BY NBS-8 TEST CASES}

\section{TEST NAMES: All tests prefixed by NBS8-R}

Filename: $\quad$ R8R

Document Type: NBS-8

File Contents: The data elements of this file are represented by:

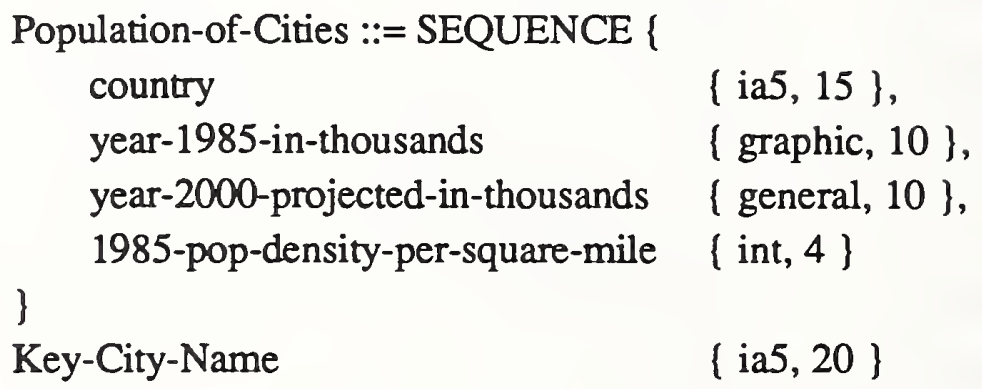

The data element values for the data units are:

\begin{tabular}{llrrr} 
Node Name & Contents & & & \\
\cline { 2 - 3 } "Los Angeles" & "U.S." & "9638" & "10714" & 8682 \\
"Manchester" & "U.K." & "4151" & "3827" & 11627 \\
"Mexico City" & "Mexico" & "16900" & "27872" & 32377 \\
"Singapore" & "Singapore" & "2556" & "2913" & 32769 \\
"Sydney" & "Australia" & "3396" & "3708" & 10047 \\
"Tokyo-Yokahama" & "Japan" & "25434" & "29971" & 23356
\end{tabular}

TEST NAME: $\quad$ NBS8-R-1

Filename: $\quad$ A8R1

Document Type: NBS-8

File Contents: Generated by running test. 
TEST NAME: $\quad$ NBS8-R-8

Filename: $\quad$ R8R8

Document Type: NBS-8

File Contents: The data elements of this file are represented by:

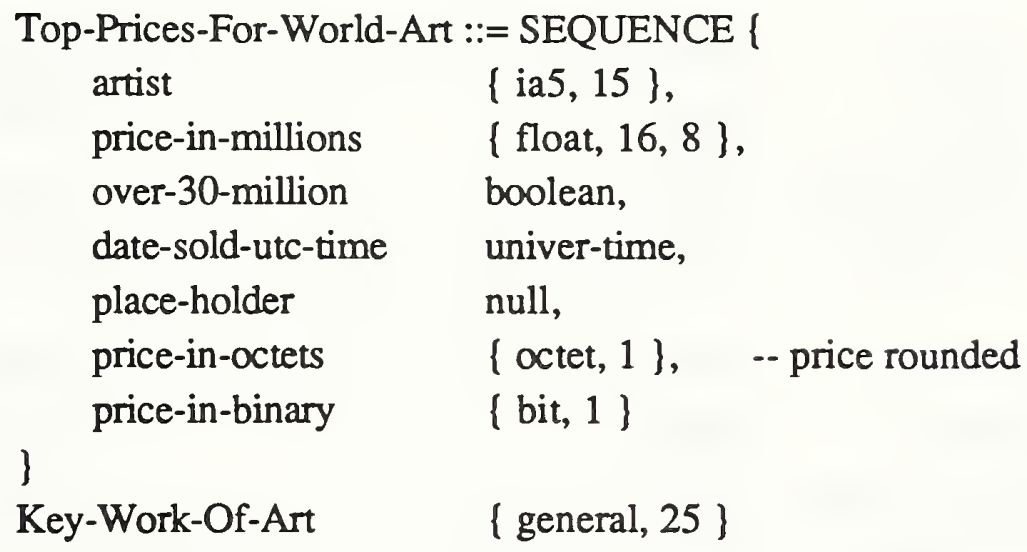

The data element values for the data units are:

Node Name Contents

"Irises" "van Gogh" 53.9 TRUE "8712101515Z" null '3C'H '111100'B

"Sunflowers" "van Gogh" 39.9 TRUE "8702181616Z" null '28'H '101000'B

"Woman Reading" "Braque" 9.5 FALSE "8604301717Z" null 'A'H '1010'B

Filename: $\quad$ A8R8

Document Type: NBS-8

File Contents: Generated by running test.

TEST NAME: $\quad$ NBS8-W-1 through NBS8-W-4

Filename: $\quad$ R8W4

Document Type: NBS-8

File Contents: Same as file R8R.

TEST NAME: $\quad$ NBS8-W-5

Filename: R8W5

Document Type: NBS-8

File Contents: $\quad$ Same as file R8R. 
NBS-8 Test Files

TEST NAME: $\quad$ NBS8-W-6

Filename: $\quad$ R8W6

Document Type: NBS-8

File Contents: Same as file R8R.

TEST NAME: $\quad$ NBS8-W-7

Filename: $\quad$ R8W7

Document Type: NBS-8

File Contents: $\quad$ Same as file R8R.

TEST NAME: $\quad$ NBS8-W-8

Filename: $\quad$ R8W8

Document Type: NBS-8

File Contents: $\quad$ Same as file R8R.

TEST NAME: $\quad$ NBS8-W-9

Filename: $\quad$ R8W9

Document Type: NBS-8

File Contents: $\quad$ Same as file R8R.

TEST NAME: $\quad$ NBS8-W-10

Filename: $\quad$ R8W10

Document Type: NBS-8

File Contents: Same as file R8R.

TEST NAME: $\quad$ NBS8-W-11

Filename: $\quad$ R8W11

Document Type: NBS-8

File Contents: Same as file R8R8.

TEST NAME: $\quad$ NBS8-RR-1

Filename: $\quad$ A8RR1

Document Type: NBS-8

File Contents: Same as file R8R. 
TEST NAME: NBS8-RR-2

Filename: $\quad$ A8RR2

Document Type: NBS-8

File Contents: Same as file R8R.

TEST NAME: $\quad$ NBS8-WW-1

Filename: $\quad$ R8WW1

Document Type: NBS-8

File Contents: Same as file R8R.

TEST NAME: $\quad$ NBS8-WW-2

Filename: $\quad$ R8WW2

Document Type: NBS-8

File Contents: Same as file R8R.

TEST NAME: $\quad$ NBS8-RW-1

Filename: $\quad$ R8RW1

Document Type: NBS-8

File Contents: $\quad$ Same as file R8R.

Filename: $\quad$ A8RW1

Document Type: NBS-8

File Contents: Generated by running test.

TEST NAME: $\quad$ NBS8-RW-2

Filename: $\quad$ R8RW2

Document Type: NBS-8

File Contents: $\quad$ Same as file R8R.

Filename: $\quad$ A8RW2

Document Type: NBS-8

File Contents: Generated by running test. 
NBS-8 Test Files

TEST NAME: $\quad$ NBS8-RW-3

Filename: $\quad$ R8RW3

Document Type: NBS-8

File Contents: Same as file R8R. 


\subsection{FILES USED BY LIMITED FILE MANAGEMENT TEST CASES}

TEST NAME: $\quad$ LFM-1

Filename: $\quad$ RLFM1

Document Type: FTAM-3, 512, 'not-significant'

File Contents: File RLFM1 is created.

\section{TEST NAME: $\quad$ LFM-2}

Filename: $\quad$ RLFM2

Document Type: FTAM-3, 512, 'not-significant'

File Contents: $\quad$ Same as file R3R1.

TEST NAME: $\quad$ LFM-3

Filename: $\quad$ RLFM3

Document Type: FTAM-3, 512, 'not-significant'

File Contents: Same as file R3R1.

TEST NAME: $\quad$ LFM-4

Filename: $\quad$ RLFM4

Document Type: FTAM-3, 512, 'not-significant'

File Contents: Same as file R3R1.

Filename: $\quad$ ILFM4

Document Type: FTAM-3, 512, 'not-significant'

File Contents: $\quad$ Same as file I3W1.

\section{TEST NAME: $\quad$ LFM-5}

Filename: $\quad$ RLFM5

Document Type: FTAM-3, 512, 'not-significant'

File Contents: Same as file R3R1.

TEST NAME: $\quad$ LFM-6

Filename: $\quad$ RLFM6

Document Type: FTAM-3, 512, 'not-significant'

File Contents: Same as file R3R1. 
TEST NAME: $\quad$ LFM-7

Filename: $\quad$ RLFM7

Document Type: FTAM-3, 512, 'not-significant'

File Contents: Same as file R3R1. Permitted actions allowed are read, replace, extend, and delete file. The read attribute permitted action can not be performed on file RLFM7.

TEST NAME: $\quad$ LFM-8

Filename: $\quad$ RLFM8

Document Type: FTAM-3, 512, 'not-significant'

File Contents: $\quad$ Same as file R3R1.

TEST NAME: $\quad$ LFM-10

Filename: $\quad$ RLFM10

Document Type: FTAM-3, 512, 'not-significant'

File Contents: Same as file R3R1. Permitted actions allowed are read, replace, and extend. The delete file permitted action is not supported for file RLFM10.

TEST NAME: $\quad$ LFM-11

Filename: $\quad$ RLFM11

Document Type: FTAM-3, 512, 'not-significant'

File Contents: Same as file R3R1.

\section{TEST NAME: $\quad$ LFM-12}

Filename: $\quad$ RLFM12

Document Type: FTAM-3, 512, 'not-significant'

File Contents: Same as file R3R1.

TEST NAME: $\quad$ LFM-13

Filename: $\quad$ RLFM13

Document Type: FTAM-3, 512, 'not-significant'

File Contents: $\quad$ Same as file R3R1.

Filename: $\quad$ ILFM13

Document Type: FTAM-3, 512, 'not-significant'

File Contents: $\quad$ Same as file $13 \mathrm{~W} 1$. 
TEST NAME: $\quad$ LFM-14

Filename: $\quad$ RLFM14

Document Type: FTAM-3, 512, 'not-significant'

File Contents: Same as file R3R1. 


\subsection{FILES USED BY ENHANCED FILE MANAGEMENT TEST CASES}

TEST NAME: $\quad$ EFM-1

Filename: $\quad$ REFM1

Document Type: FTAM-3, 512, 'not-significant'

File Contents: $\quad$ Same as file R3R1.

TEST NAME: $\quad$ EFM-2

Filename: $\quad$ REFM2

Document Type: FTAM-3, 512, 'not-significant'

File Contents: Same as file R3R1.

Filename: $\quad$ REFM2A

Document Type: FTAM-3, 512, 'not-significant'

File Contents: Same as file I3W1.

TEST NAME: $\quad$ EFM-4

Filename: $\quad$ REFM4

Document Type: FTAM-3, 512, 'not-significant'

File Contents: Same as file R3R1. Permitted actions allowed are read, replace, extend, read attribute and delete file. The change attribute permitted action can not be performed on file REFM4.

TEST NAME: $\quad$ EFM-5

Filename: $\quad$ REFM5

Document Type: FTAM-3, 512, 'not-significant'

File Contents: Same as file R3R1. The file availability storage attribute should be set to "immediate availability".

TEST NAME: $\quad$ EFM-6

Filename: REFM6

Document Type: FTAM-3, 512, 'not-significant'

File Contents: Same as file R3R1. 
TEST NAME: $\quad$ EFM-7

Filename: $\quad$ REFM7

Document Type: FTAM-3, 512, 'not-significant'

File Contents: $\quad$ Same as file R3R1. 


\section{Cross Reference Table}

The following cross reference table lists the document types and management attributes, and the possible actions that can be performed on them. For each action, the name of the corresponding test case defined in the FTAM Interoperability Tests is listed.

FTAM-1 Unstructured Constraint Set Actions (see Table 6 in ISO 8571-2) 1
Read
FTAM1-R-1, 2
Replace
FTAM1-W-1, 2
Extend
FTAM1-W-3, 4
Erase
FTAM1-WW-1

FTAM-2 Sequential Flat Constraint Set Actions (see Table 7 and 8 in ISO 8571-2)

Locate

Begin

First

Next

Read

Begin

- whole

First

Next

- leaf

- leaf

Insert

End - leaf

Erase

Begin
FTAM2-RW-1

FTAM2-RR-1, -RW-1

FTAM2-RR-1, -RW-1

FTAM2-R-1, -RR-1, -RW-1

FTAM2-RR-1

FTAM2-RR-1, -RW-1

FTAM2-W-1, -WW-1, -RW-1

FTAM-3 Unstructured Constraint Set Actions (see Table 6 in ISO 8571-2)

Read

Replace

Extend

Erase
FTAM3-R-1, 2, 3, 4, 5, 6, 7

FTAM3-W-1, 2, 3, 5

FTAM3-W-4, 5

FTAM3-WW-1

1 Test case FTAM1-R-3 tests for structural simplification, character relaxation, and string length relaxation of an FTAM-2 file. 
NBS-6 Sequential Flat Constraint Set Actions (see Table 7 and 8 in ISO 8571-2)

Locate

Begin

End

First

Next

Read

Begin - whole

First - leaf

Next - leaf

Insert

End

Erase

Begin
- leaf

- whole
NBS6-RW-1

NBS6-WW-1, -RW-1

NBS6-RR-1, -RW-1

NBS6-RR-1

NBS6-R-1, -RR-1, -RW-1

NBS6-RR-1

NBS6-RR-1, -RW-1

NBS6-W-1, -WW-1, -RW-1

NBS6-WW-2 
NBS-7 NBS Ordered Flat Constraint Set Actions (see Table 6.14 \& 6.15 in NIST Stable Agreements Document)

Locate

Begin

End

First

Last

Current

Next

Previous

Traversal

Read

$\begin{array}{ll}\text { Begin } & \text { - whole } \\ \text { First } & \text { - leaf } \\ \text { Last } & \text { - leaf } \\ \text { Current } & \text { - leaf } \\ \text { Next } & \text { - leaf } \\ \text { Previous } & - \text { leaf } \\ \text { Traversal } & - \text { leaf }\end{array}$

Insert

$\begin{array}{lll}\text { End } & \text { - leaf } \\ \text { Traversal } & - & \text { leaf }\end{array}$

Erase

Begin - whole

Replace

$\begin{array}{ll}\text { Begin } & \text { - whole } \\ \text { First } & \text { - leaf } \\ \text { Last } & \text { - leaf } \\ \text { Current } & \text { - leaf } \\ \text { Next } & \text { - leaf } \\ \text { Previous } & \text { - leaf } \\ \text { Traversal } & \text { - leaf }\end{array}$

NBS7-WW-3, -RW-1, 2, 3

NBS7-RR-1, -WW-1, -RW-1

NBS7-RR-1, -WW-1, -RW-1

NBS7-RR-1, -WW-1

NBS7-RR-2

NBS7-RR-1, 2, -WW-1

NBS7-RR-1, 2, -WW-1, -RW-1

NBS7-RR-2, -RW-1, -RW-2, 3

NBS7-R-1

NBS7-R-2

NBS7-R-3

NBS7-R-4, -RR-1, 2, -RW-1, 2, 3

NBS7-R-5

NBS7-R-6, -RR-1, -RW-1

NBS7-R-7, 8

NBS7-W-1, -WW-1, -RW-1

NBS7-W-2

NBS7-WW-2

NBS7-W-11, -WW-3

NBS7-W-3

NBS7-W-5

NBS7-W-8, -WW-1, -RW-3

NBS7-W-4, -RW-3

NBS7-W-6

NBS7-W-7, 9, 10, -RW-2 
NBS-8 NBS Ordered Flat Constraint Set Actions² (see Table 9 \& 10 in ISO 8571-2)

Locate

Begin

End

Current

Next

Previous

NodeSeq

Read

Begin - whole

Current - leaf

Next - leaf

Previous - leaf

NodeSeq - leaf

Insert

Begin - leaf

Replace

Begin

Current

Next

Previous

NodeSeq - leaf

Erase

\begin{tabular}{|c|c|}
\hline Begin & \\
\hline Current & \\
\hline Next & \\
\hline Previous & \\
\hline NodeSeq & - \\
\hline
\end{tabular}

NBS8-WW-1, -RW-1

NBS8-RR-1

NBS8-RR-2

NBS8-RR-1, 2

NBS8-RR-1, 2, -RW-1

NBS8-RR-1, 2, -WW-1, -RW-1, 2

NBS8-R-1, -RW-2

NBS8-R-2, -RR-1, 2, -RW-1

NBS8-R-3, -RR-1

NBS8-R-4, -RR-1, 2

NBS8-R-5, 6, 7, -RW-3

NBS8-W-1, 2, 3, 4, -WW-1, -RW-1

NBS8-W-5

NBS8-W-6

NBS8-W-7, -WW-1

NBS8-W-8, -WW-1

NBS8-W-9, 10, -WW-1

NBS8-WW-

NBS8-RW-2

NBS8-RW-2

NBS8-RW-2, -RW-3

NBS8-RW-2

NBS-9 Unstructured Constraint Set Actions

Read

NBS9-R-1

Limited File Management

Create File

Read Attributes

Delete File

Enhanced File Management

Change Attributes
LFM-1, 2, 3, 4, 5

LFM-6, 7, 11, 12, 13, 14

LFM-8, 9, 10

EFM-1, 2, 3, 4, 5, 6, 7

2 The FADU identities "first", "last", and "traversal" are not required for conformant implementations. 


\section{Programs Substantiating The FTAM-1 and FTAM-3 Test Files}

The following short programs substantiate the FTAM-1 test files (R1R1, R1R2, R1W1 and R1W2) and the FTAM-3 test files (R3R1, R3R2 and I3W1). The programs are written in the 'C' Programming Language.

/*

Filename: $\quad$ R1R1

Document Type: FTAM-1, 22, 134, 'not-significant'

File Contents: This file contains 50 strings. Each string consists of the "FTAM1A" followed by the 128 printable characters (in ascending order) taken from the ISO $646 \mathrm{G} 0$ character set starting with position $2 / 0$ and ending with position $7 / 14$ ( 95 characters) then beginning again with $2 / 0$ and ending with $4 / 0$ (33 characters). This results in a file that contains 6700 characters.

*/

\#include <stdio.h>

\#define PERM 0644

main0

\{

char i;

char $\mathrm{j}$;

int test_file;

/* Create test file R1R1. */

if $(($ test_file $=$ creat $(" R 1 R 1 "$, PERM $))==-1)($ printf("Can not create file R1R1. $n$ "); exit(1);

)

/* Begin writing file R1R1 out. */

for $(i=1 ; i<=50 ; i++)\{$

/* Write out "FTAM1A". */

if (write(test_file, "FTAM1A", 6) <6) \{ 


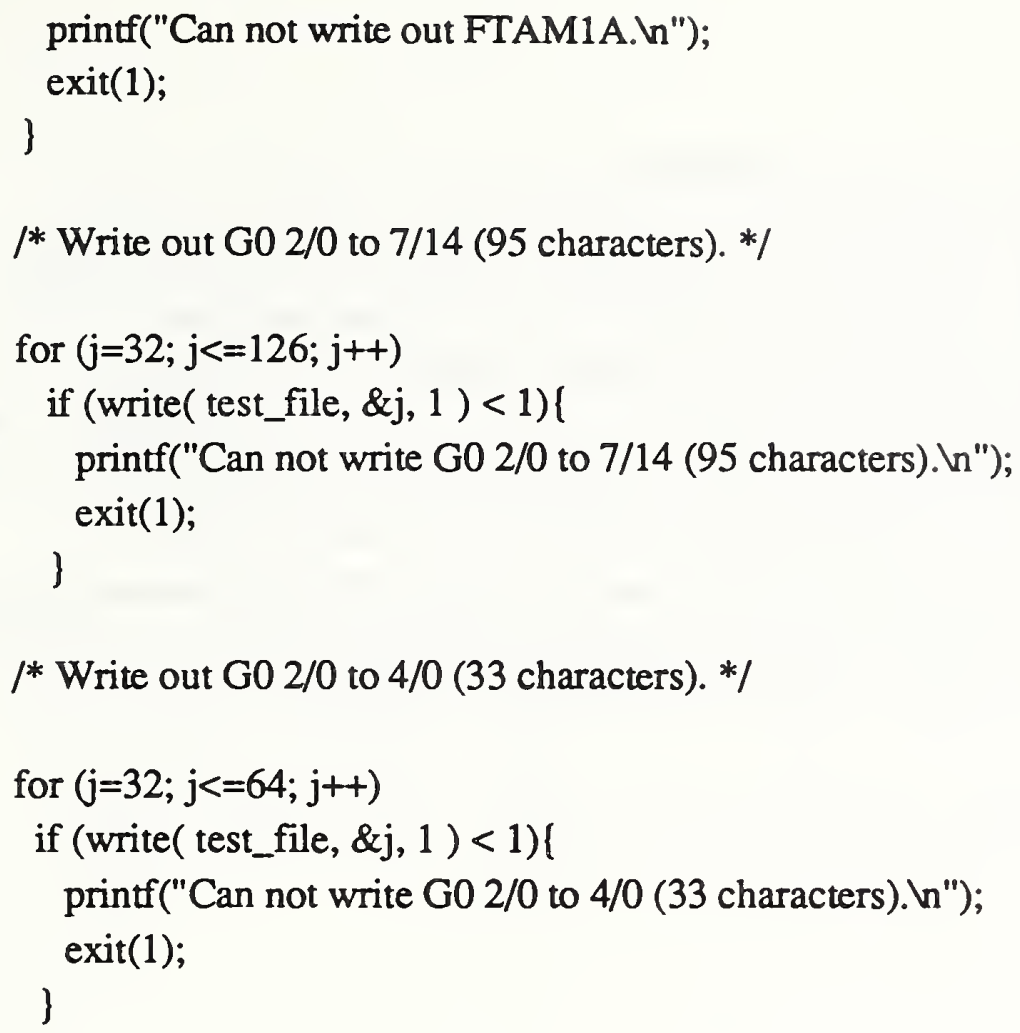

\}

close( test_file );

\} 
/*

Filename: $\quad$ R1R2

Document Type: FTAM-1, 27, 134, 'not-significant'

File Contents: This file contains 50 strings. The first 25 strings consists of the name "FTAM1C" followed by the 128 printable characters (in ascending order) taken from the ISO 8859-1 G0 and G1 character sets starting with position $2 / 0$ and ending with position $7 / 14$ (95 characters from $\mathrm{G} 0$ ) followed by the characters 10/0 through 12/0 ( 33 characters from G1). The second 25 strings consists of the name "FTAM1C" followed by the 128 printable characters (in ascending order) taken from the ISO $8859-1 \mathrm{G0}$ and $\mathrm{G} 1$ character sets starting with position $11 / 15$ and ending with position $15 / 15$ (65 characters from $\mathrm{G} 1$ ) followed by the characters $2 / 0$ through $5 / 14$ ( 63 characters from G0). This results in a file that contains 6700 characters.

$*$

\#include <stdio.h >

\#define PERM 0644

main 0

\{

unsigned char i;

unsigned char $\mathrm{j}$;

int test_file;

/* Create test file R1R2. */

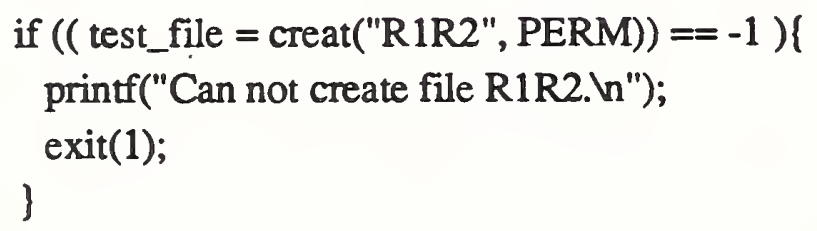

/* Begin writing file R1R2 out. */

for $(i=1 ; i<=25 ; i++)\{$

^* Write out "FTAM1C". */

if (write(test_file, "FTAM1C", 6) <6) \{ printf("Can not write out FTAM1C.hn"); exit(1); 


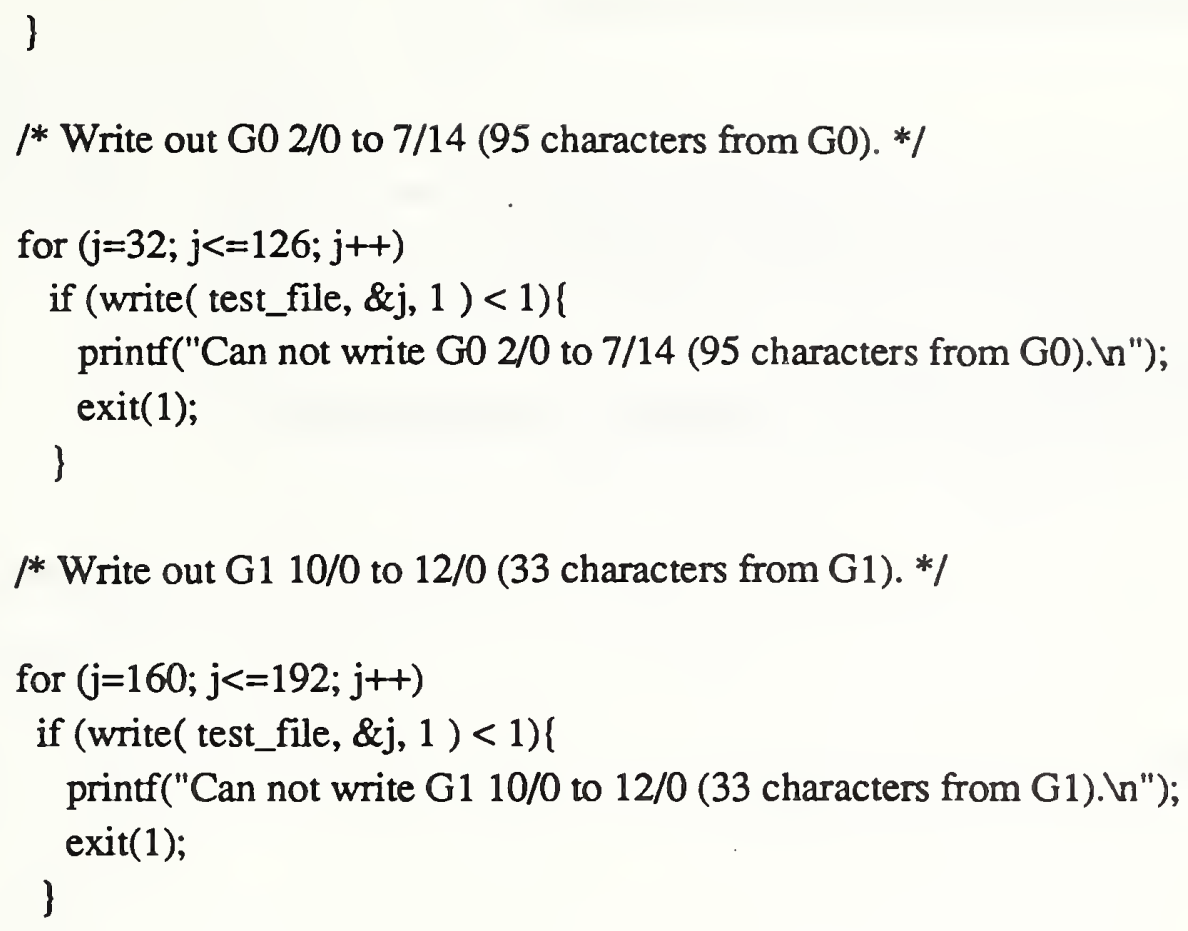

/* Write out the next 25 strings. */

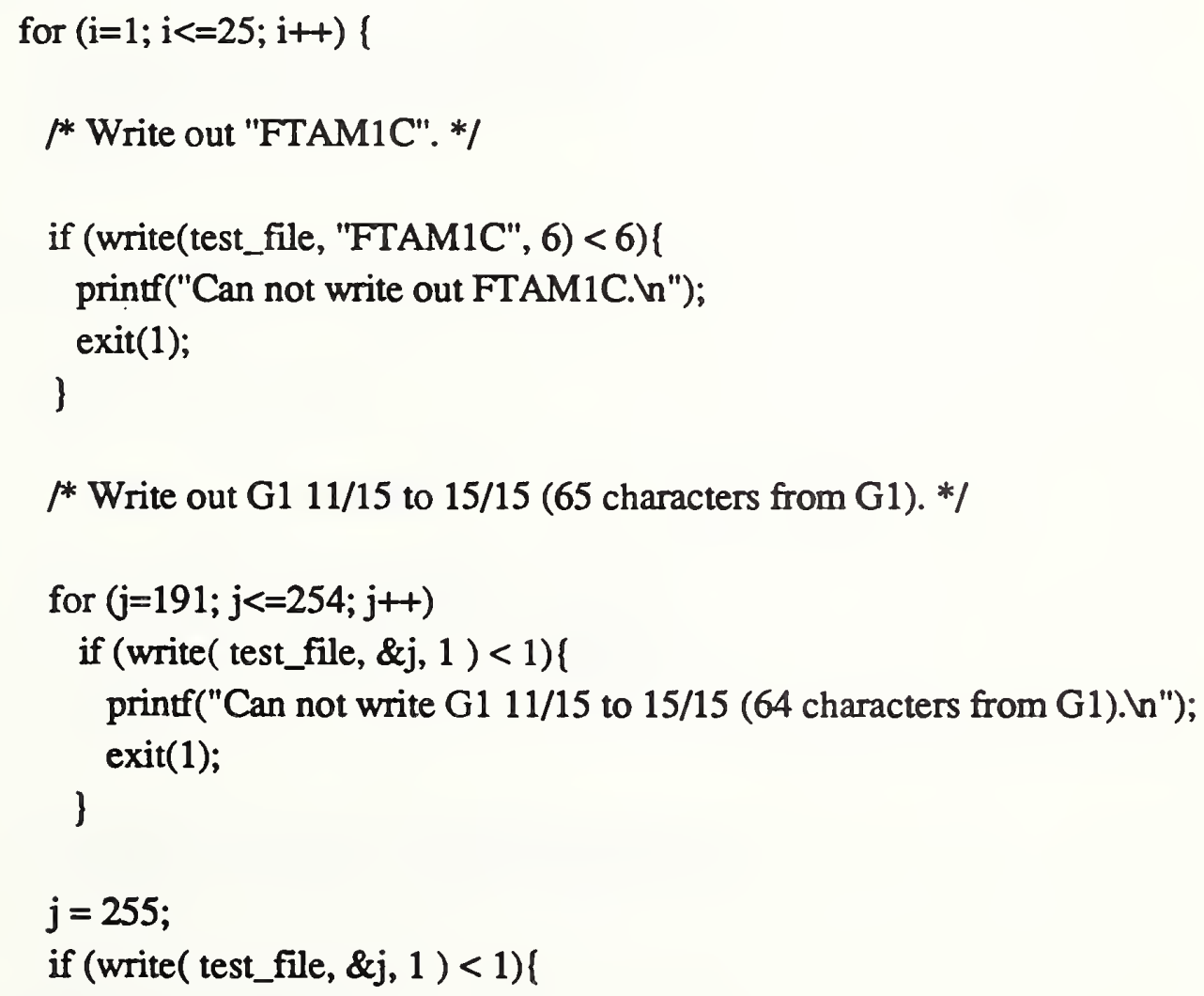


printf("Can not write G1 15/15 (1 character from G1). In"); exit(1);

\}

/* Write out G0 2/0 to $5 / 14$ (63 characters from G0). */

for $(j=32 ; j<=94 ; j++)$

if (write( test_file, $\& \mathrm{j}, 1$ ) $<1$ )

printf("Can not write G0 2/0 to 5/14 (63 characters from G0). $\mathrm{ln}$ "); exit(1);

\}

\}

close( test_file );

\} 
/*

Filename:

I1W1

Document Type: FTAM-1, 22, 134, 'not-significant'

File Contents: This file contains 50 strings. Each string consists of the name "FTAM1B" followed by the 128 printable characters (in descending order) taken from the ISO 646 G0 character set starting with position $7 / 14$ and ending with position $2 / 0$ (95 characters) then beginning again with $7 / 14$ and ending with $5 / 14$ ( 33 characters). This results in a file that contains 6700 characters.

*/

\#include <stdio.h $>$

\#define PERM 0644

main()

l

char $\mathrm{i}$;

char $\mathrm{j}$;

int test_file;

/* Create test file I1W1. */

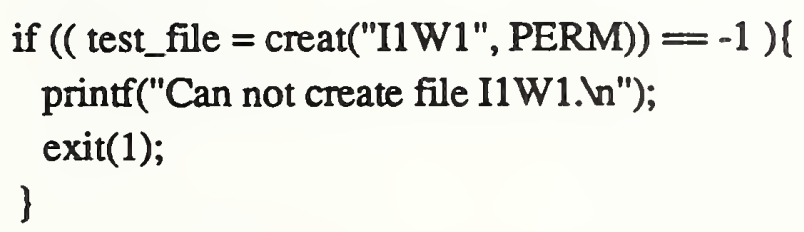

/* Begin writing file I1W1 out. */

for $(i=1 ; i<=50 ; i++)$ (

/* Write out "FTAM1B". */

if (write(test_file, "FTAM1B", 6) < 6) \{ printf("Can not write out FTAM1B. $n ") ;$ exit(1);

\}

/* Write out G0 7/14 to $2 / 0$ (95 characters). */

for $(j=126 ; j>=32 ; j-)$ 
if (write(test_file, \& j, 1 ) $<1$ ) printf("Can not write G0 2/0 to 7/14 (95 characters). In"); exit(1);

\}

/* Write out G0 7/14 to 5/14 (33 characters). */

for $(j=126 ; j>=94 ; j--)$

if (write( test_file, $\& \mathrm{j}, 1$ ) $<1$ )

printf("Can not write G0 7/14 to 5/14 (33 characters). $\operatorname{ln");~}$

exit(1);

\}

\}

close( test_file);

\} 
/*

Filename:

II W2

Document Type: FTAM-1, 27, 134, 'not-significant'

File Contents: This file contains 50 strings. The first 25 strings consists of the name "FTAM1D" followed by the 128 printable characters (in descending order) taken from the ISO 8859-1 G0 and G1 character sets starting with position $15 / 15$ and ending with position 10/0 (96 characters from G1) followed by the characters $7 / 14$ through $5 / 15$ ( 32 characters from $\mathrm{G} 0$ ). The second 25 strings consists of the name "FTAM1D" followed by the 128 printable characters (in descending order) taken from the ISO 8859-1 G0 and G1 character sets starting with position $6 / 0$ and ending with position 2/0 (65 characters from $\mathrm{G} 0$ ) followed by the characters $15 / 15$ through $2 / 1$ (63 characters from G1). This results in a file that contains 6700 characters.

*/

\#include <stdio.h $>$

\#define PERM 0644

maino

\{

unsigned char $\mathrm{i}$;

unsigned char $\mathrm{j}$;

int test_file;

/* Create test file I1W2. */

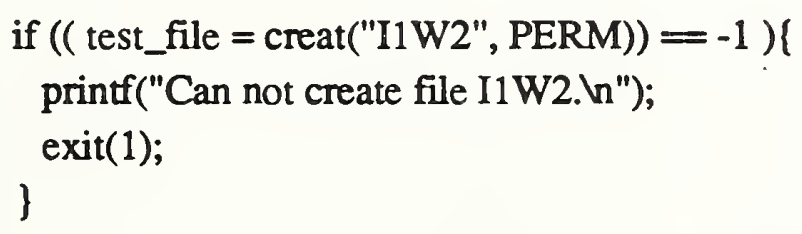

/* Begin writing file I1 W2 out. */

for $(i=1 ; i<=25 ; i++)\{$

/* Write out "FTAM1D". */

if (write(test_file, "FTAM1D", 6) < 6) ( printf("Can not write out FTAM1D.vn");

exit(1); 
\}

/* Write out G1 15/15 to 10/0 (96 characters from G1). */

$\mathrm{j}=255$;

if (write(test_file, \&j, 1 ) $<1$ ) (

printf("Can not write G1 15/15 (1 character from G1). .n");

exit(1);

\}

for $(j=254 ; j>=160 ; j--)$

if (write(test_file, \&j, 1 ) $<1$ ) (

printf("Can not write G1 15/14 to 10/0 (95 characters from G1). $\mathrm{nn");}$ exit(1);

\}

/* Write out G1 7/14 to 5/15 (32 characters from G0). */

for $(j=126 ; j>=95 ; j--)$

if (write( test_file, $\&$ j, 1 ) $<1$ ) (

printf("Can not write G1 7/14 to 5/15 (32 characters from G0). $n$ ");

exit(1);

\}

)

/* Write out the next 25 strings. */

for $(i=1 ; i<=25 ; i++)($

* Write out "FTAM1D". */

if (write(test_file, "FTAM1D", 6) <6) (

printf("Can not write out FTAM1D.hn");

exit(1);

\}

/* Write out G0 6/0 to 2/0 (65 characters from G0). */

for $(j=96 ; j>=32 ; j-)$

if (write( test_file, \&j, 1 ) $<1$ )

printf("Can not write G0 6/0 to 2/0 (65 characters from G0).ln"); 
exit(1);

\}

/* Write out G1 15/15 to $12 / 1$ (63 characters from G1). */

$\mathrm{j}=255$;

if (write( test_file, $\& \mathrm{j}, 1$ ) $<1$ ) (

printf("Can not write G1 15/15 (1 character from G1).ln");

exit(1);

\}

for $(j=254 ; j>=193 ; j--)$

if (write( test_file, $\& \mathrm{j}, 1$ ) $<1$ )

printf("Can not write G1 15/14 to 12/1 (62 characters from G1). $\backslash n "$ "); exit(1);

\}

\}

close( test_file ); 
/*

Filename: $\quad$ R3R1

Document Type: FTAM-3, 512, 'not-significant'

File Contents: This file contains 4 strings. Each string consists of the name "FTAM3A" followed by the 2568 -bit combinations in descending order from 255 to 0 followed by the 2508 -bit combinations in descending order from 249 to 0 . This results in a file of 2048 characters.

*/

\#include <stdio.h $>$

\#define PERM 0644

main()

l

char ch;

int $\mathrm{i}$;

int $\mathrm{j}$;

int test_file;

/* Create test file R3R1. */

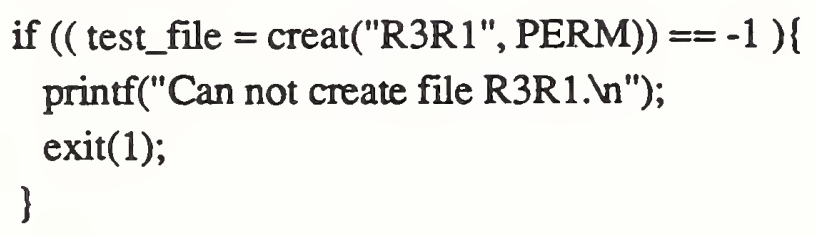

/* Begin writing file R3R1 out. */

for $(i=1 ; i<=4 ; i++)\{$

/* Write out "FTAM3A". */

if (write(test_file, "FTAM3A", 6) <6) \{ printf("Can not write out FTAM3A.เn"); exit(1);

)

/* Write from position 255 to position 0. */

for $(j=255 ; j>=0 ; j--)($ 


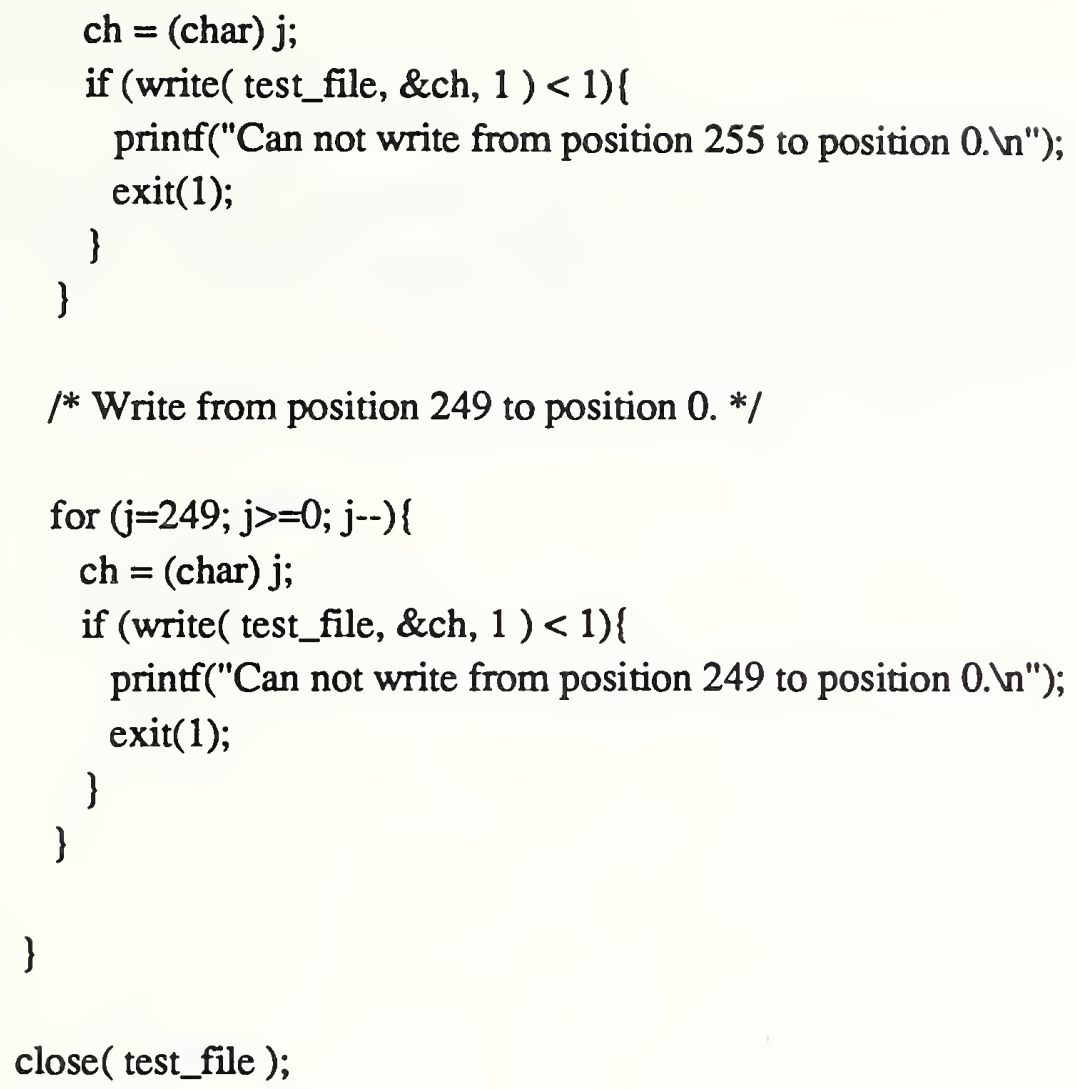




\section{/*}

Filename: $\quad$ R3R3

Document Type: FTAM-3, 512, 'not-significant'

File Contents: $\quad$ This file contains 1540 strings. Each string consists of the name "FTAM3B" followed by the 2568 -bit combinations in ascending order from 0 to 255 followed by the 2508 -bit combinations in ascending order from 0 to 249 . This results in a file of 788,480 characters.

$* /$

\#include <stdio.h $>$

\#define PERM 0644

main()

l

char ch;

register int $i$;

register int $\mathrm{j}$;

int test_file;

/* Create test file R3R2. */

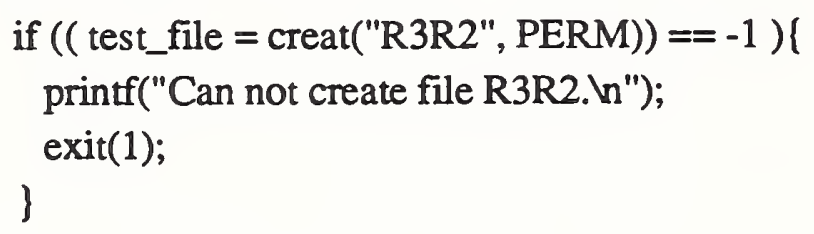

/* Begin writing file R3R2 out. */

for $(i=1 ; i<=1540 ; i++)\{$

/* Write out "FTAM3B". */

if (write(test_file, "FTAM3B", 6) < 6) \{ printf("Can not write out FTAM3B.เn"); exit(1);

\}

/* Write from position 0 to position 255 . */

for $(j=0 ; j<=255 ; j++)($ 


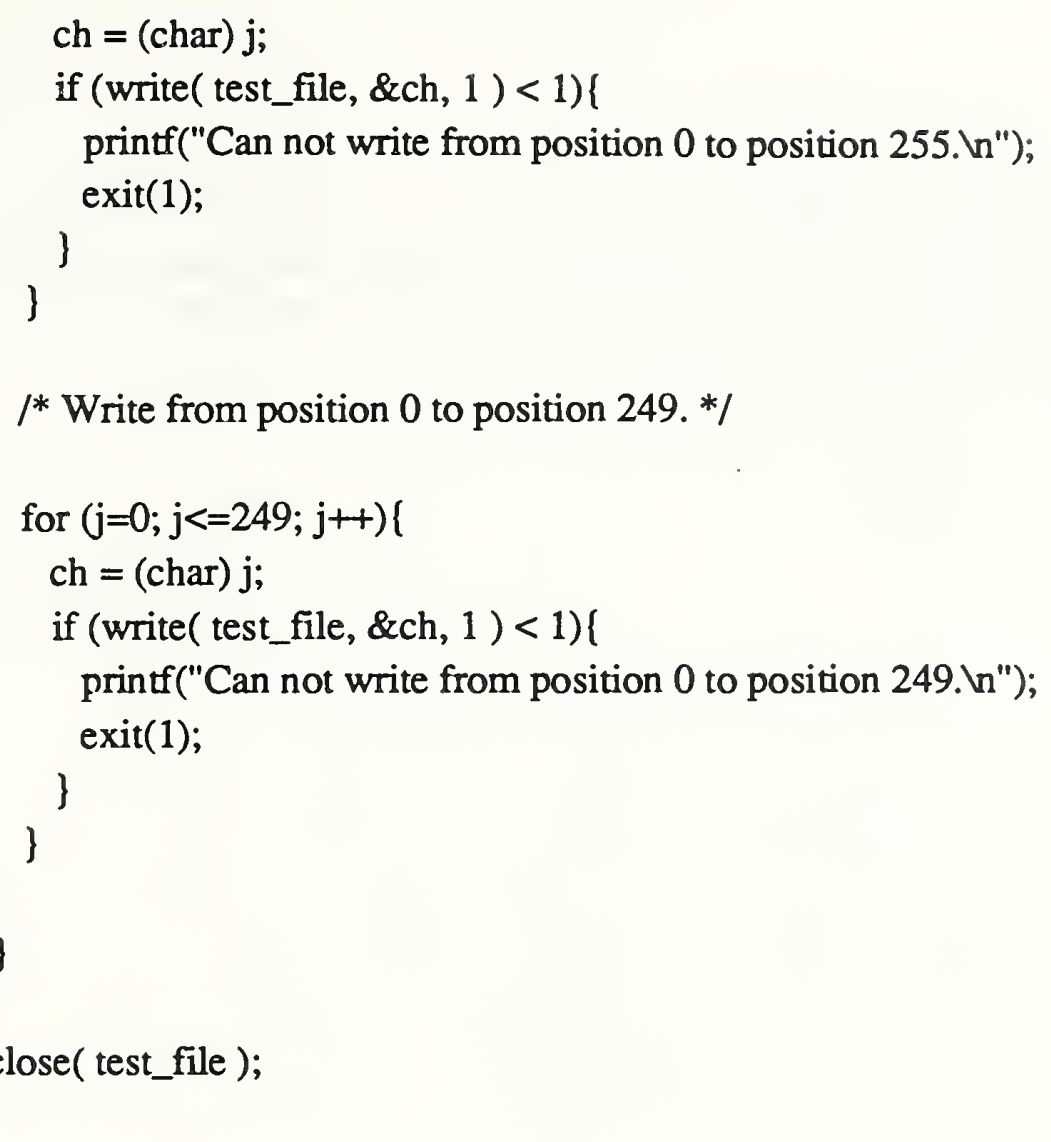


*

Filename:

I3W1

Document Type: FTAM-3, 512, 'not-significant'

File Contents: $\quad$ This file contains 4 strings. Each string consists of the name "FTAM3C" followed by the 2568 -bit combinations in ascending order from 0 to 255 followed by the 250 8-bit combinations in ascending order from 0 to 249 . This results in a file of 2048 characters.

*1

\#include <stdio.h $>$

\#define PERM 0644

main()

l

char ch;

register int $\mathrm{i}$;

register int $\mathrm{j}$;

int test_file;

/* Create test file I3W1. */

if $(($ test_file $=$ creat ("I3W1", PERM)) $=-1)($ printf("Can not create file I3W1. $(n$ "); $\operatorname{exit}(1)$;

)

/* Begin writing file I3W1 out. */

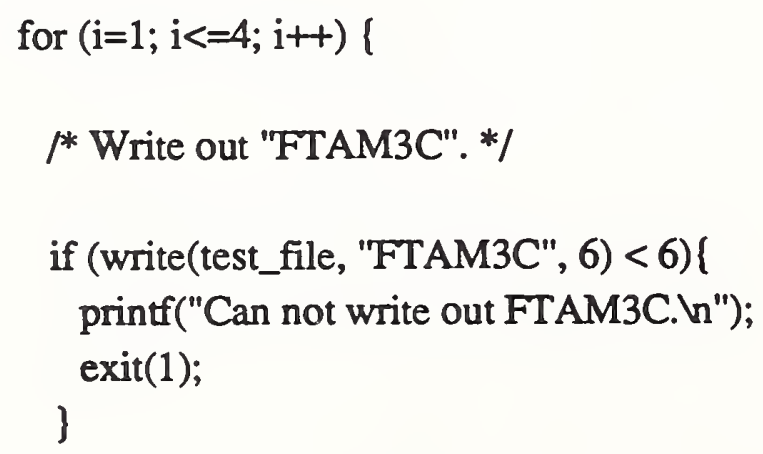

/* Write from position 0 to position 255 . */

for $(j=0 ; j<=255 ; j++)($ 


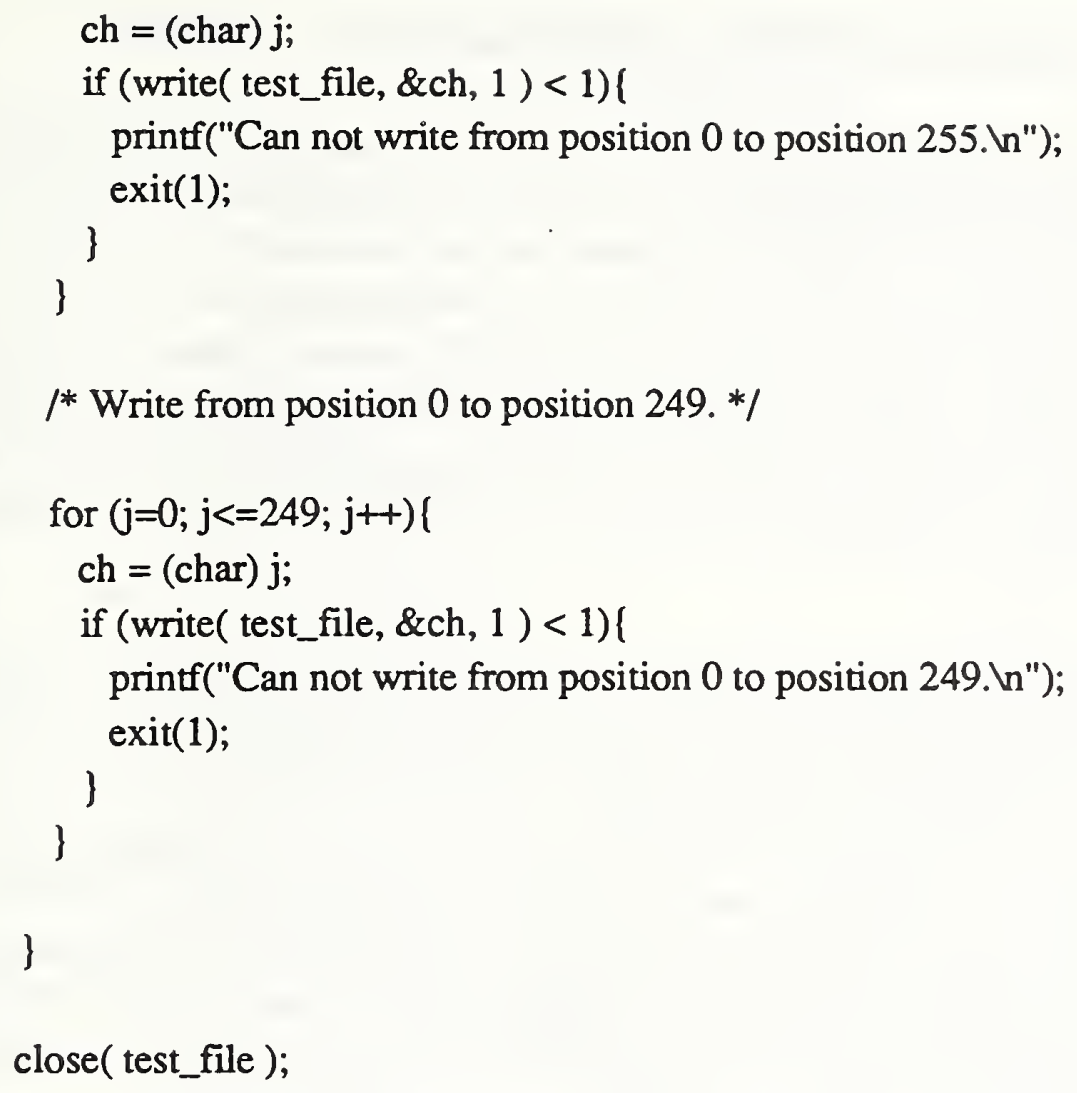




\section{Appendix A. FTAM Interoperability Requirements for GOSIP}

The FTAM tests are grouped according to type of system (limited-purpose (LP) or full-purpose (FP)) and implementation roles (initiator-sender, responder-receiver, initiator-receiver or responder-sender). Since there are two types of systems and initiator-senders will test with responder-receivers (Group 1) and initiator-receivers will test with responder-senders (Group 2), the tests are divided into four tables. Table 1 gives the tests for FP systems - Group 1, Table 2 gives the for LP systems - Group 2, Table 3 gives the tests for FP systems - Group 1, and Table 4 gives the tests for FP systems - Group 2. Within each table, tests are organized in terms of the implementation profiles specified in Section 4.2.7.2 of GOSIP and Sections 9.18 and 9.19 of the Workshop Agreements.

A limited-purpose system implementing all of the roles must pass all of the tests in Table 1 and 2. A limited-purpose system implementing a subset of the roles must pass all of the tests in Table (1 or 2) corresponding to the roles that were implemented. For each role in Table 1 and/or 2 implemented, the appropriate tests must be passed for that role. A full-purpose system implementing all of the roles must, in addition, pass all of the tests in Table 3 and 4 as indicated. A full-purpose system implementing a subset of the roles must, in addition, pass all of the tests in the table ( 3 or 4 ) corresponding to the roles that were implemented. For each role in Table 3 and/or 4 implemented, the appropriate tests must be passed for that role. Full-purpose systems must pass limited-purpose tests for each defined role. This is assumed by the tables. 


\section{LP SYSTEMS - GROUP 1 TESTS \\ TABLE 1}

IEST

FTAM1-W-1

FTAM1-W-2

FTAM1-W-3

FTAM1-W-4

FTAM3-W-1

FTAM3-W-2

FTAM3-W-3

FTAM3-W-4

*LFM-1

*LFM-2

*LFM-3

*LFM-4

*LFM-5

*LFM-6

*LFM-8

*EFM-1

*EFM-2
MPLEMENTATION PROFILE

T1

T1

T1

T1

T1

T1

T1

T1

M1

M1

M1

M1

M1

M1

M1

M1

M1

* Duplicate of test in Table 2, skip (for initiator) if this test has been previously passed (as initiator). Skip (for responder) if this test has been passed as responder.

Note: Only one of LFM-2, LFM-3, LFM-4, or LFM-5 needs to be passed. 


\section{LP SYSTEMS - GROUP 2 TESTS}

TABLE 2

TEST

FTAM1-R-1

FTAM1-R-2

FTAM3-R-1

FTAM3-R-2

FTAM3-R-3

FTAM3-R-4

FTAM3-R-5

*LFM-1

*LFM-2

*LFM-3

*LFM-4

*LFM-5

*LFM-6

*LFM-8

*EFM-1

*EFM-2
IMPLEMENTATION PROFILE

T1

T1

T1

T1

T1

T1

T1

M1

M1

M1

M1

M1

M1

M1

M1

M1

* Duplicate of test in Table 1, skip (for initiator) if this test has been previously passed (as initiator). Skip (for responder) if this test has been passed as responder.

Note: Only one of LFM-2, LFM-3, LFM-4, or LFM-5 needs to be passed.

Note 2: Test case FTAM1-R-3 is recommended to demonstrate interoperability between a limited-purpose and full-purpose system. This test can only be run if the responder supports the FTAM-2 document type. 
FP SYSTEMS - GROUP 1 TESTS

TABLE 3

TEST

AFTAM1-W-1

AFTAM1-W-2

FTAM2-W-1

AFTAM2-W-1

AFTAM2-RW-1

AFTAM2-WW-1

AFTAM3-W-1

AFTAM3-W-2

AFTAM3-W-3

AFTAM3-W-4

AFTAM3-WW-1
IMPLEMENTATION PROFILE

A1

A1

T2

A1

A1

A1

A1

A1

A1

A1

A1

FP SYSTEMS - GROUP 2 TESTS

TABLE 4

TEST

AFTAM1-R-1

FTAM2-R-1

AFTAM2-R-1

AFTAM2-RR-1

AFTAM2-RW-1

AFTAM3-R-1

AFTAM3-R-2

AFTAM3-R-3

AFTAM3-R-4
IMPLEMENTATION PROFILE

A1

T2

A1

A1

A1

A1

Al

A1

A1

Note: Each FP system must pass all of the ' $A$ ' tests in both tables 3 and 4 for each role implemented.

Note 2: AFTAM2-RW-1 is duplicated in tables 3 and 4 and only needs to be passed once. 


\section{Appendix B. Connection Parameters}

Appendix B defines the connection parameters for each of the NIST Implementation Profiles.

\section{NIST Implementation Profile T1}

Group Summary This group tests the simple file transfer capability.

\section{Profile Connection Parameters}

Initiator The initiator establishes a connection with the responder, proposing according to its capability:

- the Transfer service class or the Transfer, Management, Transfer and Management service class;

- at least the kernel file attribute group;

- at least the kernel, read and/or write, and grouping functional units; and,

- at least the abstract syntax for FTAM-1 and FTAM-3 contents types, other contents types may be proposed.

Responder The responder accepts a connection with the initiator, negotiating down as necessary, but must support:

- the Transfer service class;

- the kemel file attribute group;

- the kernel, read and/or write, and grouping functional units; and,

- the abstract syntax for FTAM-1 and FTAM-3 contents types.

\section{NIST Implementation Profile T2}

Group Summary This group tests the positional file transfer capability.

\section{Profile Connection Parameters}

Initiator The initiator establishes a connection with the responder, proposing according to its capability:

- the Transfer service class or the Transfer, Management, Transfer and Management service class;

- at least the kernel file attribute group;

- at least the kernel, read and/or write, and grouping functional units; and, 
- at least the abstract syntax for FTAM-1, FTAM-2, and FTAM-3 contents types, other contents types may be proposed.

Responder The responder accepts a connection with the initiator, negotiating down as necessary, but must support:

- the Transfer service class;

- the kernel file attribute group;

- the kernel, read and/or write, and grouping functional units; and,

- the abstract syntax for FTAM-1, FTAM-2, and FTAM-3 contents types.

The NBS-6, NBS-7 and NBS-9 contents types may be accepted if they are supported.

\section{NIST Implementation Profile A1}

Group Summary This group tests the simple file access capability.

Profile Connection Parameters

Initiator The initiator establishes a connection with the responder, proposing according to its capability:

- at least the Access service class;

- at least the kernel file attribute group;

- at least the kernel, read, write, and file access functional units; and,

- at least the abstract syntax for FTAM-1, FTAM-2, and FTAM-3 contents types, other contents types may be proposed.

Responder The responder accepts a connection with the initiator, negotiating down as necessary, but must support:

- the Access service class;

- the kernel file attribute group;

- the kernel, read, write, and file access functional units; and,

- the abstract syntax for FTAM-1, FTAM-2, and FTAM-3 contents types.

The NBS- 6 and NBS-7 contents types may be accepted if they are supported. 


\section{NIST Implementation Profile M1}

Group Summary This group tests the file management capability.

\section{Profile Connection Parameters}

Initiator

The initiator establishes a connection with the responder, proposing according to its capability:

- at least the Management service class;

- the kernel file attribute group;

- optionally, the storage and/or security file attribute groups;

- the kernel, limited file management, enhanced file management, and grouping functional units; and,

- the abstract syntax for FTAM-3 contents type.

Note 1 In addition to the connection parameters given above, test case LFM-4 requires the use of the Transfer service class with Write functional units.

Note 2 LFM-12 test case requires the read functional unit.

Note 3 LFM-13 test case requires the write functional unit.

Responder The responder accepts a connection with the initiator, negotiating down as necessary, but must support:

- the Management service class;

- the kernel file attribute group;

- the kernel, limited file management, enhanced file management, and grouping functional units; and,

- the abstract syntax for FTAM-3 contents type. 


\section{References}

[1] ISO 8571-1, Information Processing Systems - Open Systems Interconnection - File Transfer, Access and Management - Part 1: General Introduction, International Organization for Standardization (ISO), First Edition, 1 October 1988.

[2] ISO 8571-2, Information Processing Systems - Open Systems Interconnection - File Transfer, Access and Management - Part 2: Virtual Filestore Definition, International Organization for Standardization (ISO), First Edition, 1 October 1988.

[3] ISO 8571-3, Information Processing Systems - Open Systems Interconnection - File Transfer, Access and Management - Part 3: File Service Definition, International Organization for Standardization (ISO), First Edition, 1 October 1988.

[4] ISO 8571-4, Information Processing Systems - Open Systems Interconnection - File Transfer, Access and Management - Part 4: File Protocol Specification, International Organization for Standardization (ISO), First Edition, 1 October 1988.

[5] Dempsey, John P., editor, FTAM Interoperability Requirements, OSINET Technical Committee, Version 1, Edition 2, June 1990.

[6] Dempsey, John P., editor, OSINET FTAM Interoperability Tests, Stable Test Cases, OSINET Technical Committee, Version 1, Edition 2, June 1990.

[7] Recommendation T.50 International Alphabet Number 5, Consultive Committee International Telegraph and Telephone (CCITT), 1984.

[8] ISO 646, 7-BIT Coded Character Set for Information Processing Interchange, International Organization for Standardization (ISO), 1983.

[9] ISO 8859-1, 8-Bit Single-byte Coded Graphic Character Sets - Part 1: Latin Alphabet Number 1, International Organization for Standardization (ISO), 1987.

[10] ISO 2022, 7-bit and 8-bit Coded Character Sets - Code Extension Techniques, International Organization for Standardization (ISO), 1986.

[11] ISO 8824, Information Processing Systems - Open Systems Interconnection Specification of Abstract Syntax Notation One (ASN.1), International Organization for Standardization (ISO), 19 May 1987. 

. 


\begin{tabular}{|c|c|c|}
\hline \multirow[t]{3}{*}{$\begin{array}{l}\text { NIST-114A } \\
\text { (REV. 3-89) }\end{array}$} & \multirow{3}{*}{$\begin{array}{l}\text { U.S. DEPARTMENT OF COMMERCE } \\
\text { NATIONAL INSTITUTE OF STANDARDS AND TECHNOLOGY } \\
\text { BIBLIOGRAPHIC DATA SHEET }\end{array}$} & $\begin{array}{l}\text { 1. PUBLCATION OR REPORT NUMBER } \\
\text { NISTIR } 4435\end{array}$ \\
\hline & & 2. PERFORMING ORQANIZATION AEPORT NUMBER \\
\hline & & $\begin{array}{l}\text { 3. PUBUCATION DATE } \\
\text { OCTOBER } 1990\end{array}$ \\
\hline
\end{tabular}

\section{FTAM INTEROPERABILITY TESTS}

5. AUTHOR(S)

6. PERFORMINO ORGANIZATION (IF JOINT OR OTHER THAN NIST, SEE INSTRUCTIONS) U.S. DEPARTMENT OF COMMERCE NATIONAL INSTITUTE OF STANDARDS AND TECHMOLOGY GAITMERSBURQ, MD 20899 7. CONTRACT/GRANT NUMBER

8. TYPE OF REPORT AND PEAIOD COVERED

9. SPONSORING ORGANIZATION NAME AND COMPLETE ADDRESS (STAEET, CITY, STATE, ZIP)

10. SUPPLEMENTARY NOTES

DOCUMENT DESCRIBES A COMPUTER PROGRAM; SF-185, FIPS SOFTWARE SUMMARY, IS ATTACHED.

11. ABSTRACT (A 200-WOAD OR LESS FACTUAL SUMMAAY OF MOST SIGNIFICANT INFORMATION. IF DOCUMENT INCLUDES A SIGMIFICANT BIBUOGRAPHY OR LTERATURE SURVEY, MENTION IT HERE.)

This is the File Transfer, Access and Management (FTAM) Interoperability

Test suite that was originally developed by the osINET Technical Committee.

12. KEY WORDS (6 TO 12 ENTRIES; ALPHABETICAL ORDER; CAPITALZE ONLY PROPER NAMES; AND SEPARATE KEY WORDS BY SEMICOLONS)

Connections, FTAM, Interoperability, OSINET, Test Cases, Test Suites

FOR OFFICIAL DISTRIBUTION. DO NOT RELEASE TO NATIONAL TECMNICAL INFORMATION SERVICE (NTIS).

ORDER FROM SUPERINTENDENT OF DOCUMENTS, U.S. GOVERNMENT PRINTING OFFICE, WASHINOTON, DC 20402.

ORDER FROM MATIONAL TECMNICAL INFORMATION SEAVICE (NTIS), SPAINGFIELD, VA 22161.

13

15. PRICE 


